\title{
₹USGS
}

\section{Evaluation of airborne}

thermal-infrared image data

for monitoring aquatic

habitats and cultural

resources within the Grand

Canyon

by Philip A. Davis ${ }^{1}$

Open-File Report 02-367

2002

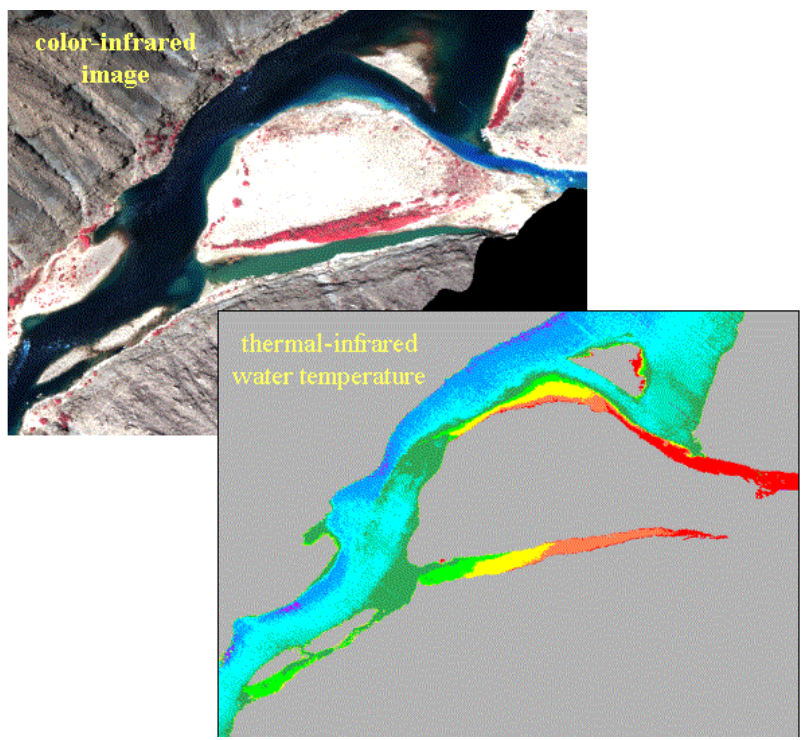

This report is preliminary and has not been reviewed for conformity with U.S. Geological Survey editorial standards or with the North American Stratigraphic Code. Any use of trade, firm, or product names is for descriptive purposes only and does not imply endorsement by the U.S. Government.

U.S. DEPARTMENT OF THE INTERIOR

U.S. GEOLOGICAL SURVEY

${ }^{1}$ Flagstaff, Arizona 


\begin{abstract}
This study examined thermal-infrared (TIR) image data acquired using the airborne Advanced Thematic Mapper (ATM) sensor in the afternoon of July $25^{\text {th }}, 2000$ over a portion of the Colorado River corridor to determine the capability of these $100-\mathrm{cm}$ resolution data to address some biologic and cultural resource requirements for GCMRC. The requirements investigated included the mapping of warm backwaters that may serve as fish habitats and the detection (and monitoring) of archaeological structures and natural springs that occur on land. This report reviews the procedure for calibration of the airborne TIR data to obtain surface water temperatures and shows the results for various river reaches within the acquired river corridor. With respect to mapping warm backwater areas, our results show that TIR data need to be acquired with a gain setting that optimizes the range of temperatures found within the water to increase sensitivity of the resulting data to a level of $0.1^{\circ} \mathrm{C}$ and to reduce scan-line noise. Data acquired within a two-hour window around maximum solar heating (1:30 PM) is recommended to provide maximum solar heating of the water and to minimize cooling effects of late-afternoon shadows. Groundtruth data within the temperature range of the warm backwaters are necessary for calibration of the TIR data. The ground-truth data need to be collected with good locational accuracy. The derived watertemperature data provide the capability for rapid, wide-area mapping of warm-water fish habitats using a threshold temperature for such habitats.
\end{abstract}

The collected daytime TIR data were ineffective in mapping (detecting) both archaeological structures and natural springs (seeps). The inability of the daytime TIR data to detect archaeological structures is attributed to the low thermal sensitivity $\left(0.3^{\circ} \mathrm{C}\right)$ of the collected data. The detection of subtle thermal differences between geologic materials requires sensitivities of at least $0.1{ }^{\circ} \mathrm{C}$, which can be obtained by most TIR sensors using an appropriate gain setting. Simultaneous data collection for both land and water purposes can be achieved using sensors that collect TIR data in two separate channels, each channel using a gain setting most appropriate for land or water. The detection of archaeological structures and natural water seeps would also be improved by collection of data after sunset, which would require a separate data acquisition from that providing surface water temperature data and therefore additional cost.

At this point, the cost for acquiring TIR data is quite high (\$620/river-km) compared to the potential benefits of the data, unless reflected-wavelength data are also collected that can satisfy other GCMRC protocol requirements (such as mapping riparian vegetation). This is especially true if multiple data acquisitions are required during the year for temporal analyses of backwater areas. The cost for these data cannot be totally mitigated by its ability to partly replace the need for ground surveys of backwaters because calibration of the TIR data will require some ground-truth data from warm backwater areas (in addition to low-temperature main-stem data). However, the airborne data can provide a product that cannot be approached by ground surveys, that being an instantaneous ( 2 hour) map of surface water temperature over a $160-\mathrm{km}$ stretch of the Grand Canyon.

\title{
Introduction
}

The Grand Canyon Monitoring and Research Center (GCMRC) of the U.S. Geological Survey studies the effects of water release from Glen Canyon Dam on the ecology of the Colorado River within the Grand Canyon (from Lake Powell to Lake Mead) in order to develop release protocols that minimize any adverse effects on the river's ecology. These studies began when the dam became operational a few decades ago, originally under the Glen Canyon Environmental Studies (GCES) group. The GCMRC is concerned with preservation issues related to (1) terrestrial vegetation habitats; (2) aquatic food base and 
habitats; (3) sediment movement and storage (within the river channel and along the shore); and (4) cultural resources (e.g., archaeological and historic monuments, springs, and mineral deposits). In terms of aquatic habitats, the biologic monitoring program has relied mostly on in-situ instrument measurements at several selected sites along the river corridor and at the mouths of major tributaries. Various chemical, electrical, optical, and thermal parameters of the water are measured every 20 minutes and downloaded periodically. Although remote-sensing data cannot detect many of the parameters that are currently being monitored by the aquatic scientists, airborne remote-sensing data can provide widearea maps of surface water temperature and water quality (e.g., turbidity, suspended load) that can indicate areas conducive to fish habitation. Currently, remote-sensing data in the form of aerial photography are used to monitor changes in debris fans and riffles along the Colorado River, which provide favorable feeding areas for fish.

The cultural resource program is concerned with preservation of materials that are relatively small in areal extent (e.g., singular occurrences of certain plants, petroglyphs, or mineral deposits) and many of which are not often within the line-of-sight (some structures are partly buried by alluvium) of an airborne sensor. For these reasons, the cultural monitoring program has correctly relied mostly on in-situ field surveys. However, some of the larger cultural features, such as springs and archaeological structures, may be detected and monitored using an airborne sensor under appropriate conditions (time of day, spatial resolution, and wavelength). Therefore, this study examines the capability of airborne thermalinfrared image data to supplement the current water-temperature monitoring program and to assist in the detection of unknown springs and in the detection and monitoring of archaeological structures. However, the river corridor monitored by GCMRC extends for $450 \mathrm{~km}$ and therefore cost for calibrated, thermalinfrared image data, at a useful spatial resolution, is a major concern that is also considered.

This study is part of the GCMRC remote-sensing initiative that began in the fall of 1999 to study the capabilities and cost-benefits of various types of multiple-wavelength remote-sensing data for different monitoring program objectives. In-situ monitoring of many of the water parameters and cultural features will probably never be replaced with an airborne remote-sensing technique due to the factors mentioned above, but remotely sensed data can, in many instances, provide a cost-effective means of providing an instantaneous map of a particular parameter over a very large area and at a sample density that cannot be approached by ground surveys. Remote-sensing data can also supplement field surveys for particular resources that are (1) difficult to reach on the ground (such as springs) or (2) not apparent on the ground (such as the occurrence of an archaeological structure covered by a few meters of alluvium). One of the main objectives of the remote-sensing initiative during 2000 was collection of calibrated thermal-infrared image data over a segment of the Grand Canyon that provided several test areas for different GCMRC monitoring protocols. This particular study examined the thermal-infrared image data that were collected to determine (1) the capability of these data to accurately measure river temperatures and map near-shore, warm-water areas that would be conducive to fish habitation, (2) the capability of the data to detect springs and to detect exposed (and possibly partly buried) archaeological structures in order to monitor the effects of erosion on these structures, and (3) the cost of such data relative to the data's potential for providing improved resource monitoring. 


\section{Previous Studies}

Civilian applications of thermal-infrared (TIR) image data began in the late 1970's with the launch of weather satellites and SEASAT and increased in the 1980's with Landsat 4 and 5 and the Heat Capacity Mapping Mission and with the development of airborne multiple-wavelength thermal imaging systems (e.g., Gillespie and Kahle, 1977; Kahle and Alley, 1985; Schott, 1989; Watson, 1992a,b). Satellite systems provide low-resolution TIR data (tens of meters per picture element) because the sensor has to integrate over a large surface area to achieve an acceptable signal-to-noise ratio. This is also the case for airborne systems such that TIR imagery is usually at a lower resolution than visible and shortwave infrared (SWIR) imagery acquired with the same sensor. Much of the research using multispectral TIR data has concentrated on geologic and organic chemical problems because TIR data are particularly sensitive to molecular vibrational differences at various TIR wavelengths. Single, broad-band TIR data have been used mostly to monitor or detect thermal anomalies associated with thermal (power-generator effluent) or chemical (oil slicks) pollution in aquatic environments. The use of hand-held thermal radiometers has also proven useful in this regard because they are relatively inexpensive to deploy. In all cases, such data are considered to complement, not be a substitute for, in-situ temperature measurements (McManus et al., 1999).

Three TIR studies were previously performed on the Colorado River within the Grand Canyon using FLIR (forward-looking infrared) and multispectral scanner data (Holroyd, 1995a, b; Eckhardt, 1998). The FLIR data were acquired using a helicopter in the early morning (6:30-7:30AM) and late afternoon (5:18-6:13PM) hours on May 24, 1994 over an 18-mile segment of the Little Colorado River. The multispectral data were acquired in the afternoon (between 1:30PM and 3:58PM) on May 29,1995 using a fixed-wing aircraft and on September 1, 1996 using a helicopter. The multispectral scanner used in these studies was the Daedalus ATM 1268 sensor; the same sensor used in the present study. The multispectral scanner data were acquired over river miles 42-48 and 60-72.

The FLIR data were obtained to determine if such data were useful for detection of warm springs along the Little Colorado River. Although the 1-m resolution FLIR data successfully detected many possible unknown springs, in addition to a single known occurrence of a spring, the poor locational accuracy provided by the FLIR system made it extremely difficult to determine the geographic location of the springs and to verify their existence. Temperature calibration and image noise were also noted as major difficulties with using the FLIR data (Holroyd, 1995a,b).

The ATM multispectral data acquisitions were also error prone. The 1.9-m resolution, 1995 data acquisition occurred under significant cloud cover with scattered thunderstorms. The Geometric Correction System (developed by DOE) was not working so rectification was impossible at that time because an orthophoto base did not exist. The $0.63-\mathrm{m}$ resolution, 1996 data acquisition was also acquired under mostly cloudy skies and the gains and offsets for the two TIR channels were set so high that temperatures below $14^{\circ} \mathrm{C}$ were not detected (temperatures within the main stem at some river reaches were near $11^{\circ} \mathrm{C}$ at that time). Funding prevented analysis of most of the data except for a single river reach at GCES Site 5. In addition, there were no ground-truth temperature data available during the 1996 overflight. Another problem with the data included difficulty in the removal of banding (striping) within the water data. This is a common problem in TIR data because of the low signal-to-noise provided by TIR data. Eckhardt (1998) was able to reduce the scanline noise using a combination of digital filters because the data were not rectified prior to delivery and therefore the image scanlines were still horizontal. Eckhardt (1998) used the near-infrared band to remove land picture elements, but noted that 
manual post-processing was necessary to remove particular land picture elements and to restore some water picture elements that were removed by the simple mask. Eckhardt (1998) noted that ground truthing within backwater areas was not possible due to the lack of locational information for the ground surveys and the difference in times between aerial and ground surveys. He also stated that the calibrated, helicopter-based multispectral data were superior to the FLIR data and recommended the calibrated data over the FLIR data, even though the cost for the calibrated data was $\$ 352-430 /$ river-km versus $\$ 46 /$ river$\mathrm{km}$ for the FLIR data for 100-mile surveys. Eckhardt suggested that the cost for data could be reduced by delivering unrectified data, which would also allow correction of scanline noise.

TIR data have also been used to detect thermal anomalies on land produced by buried structures or by ground disturbance, both of which have relevance to GCMRC cultural resource monitoring. Several studies have used TIR data to detect the presence of buried structures, both manmade and natural. For example, TIR data have been used to detect alluvium-covered, ashfall mounds that were used for Sinagua agriculture (Berlin et al., 1977, 1990). TIR data have also detected linear bedrock structures that were buried by $2 \mathrm{~m}$ of alluvium, as long as the thermal sensor could detect temperature differences at the $0.1^{\circ} \mathrm{C}$ level (Nash, 1985). TIR data have also been shown to detect subtle disturbances of soil that are not visible to the human eye, which may be useful in detecting subtle natural or unnatural disturbances at GCMRC cultural-resource sites (Johnson et al., 1998).

The current study re-deployed the Daedalus ATM 1268 multispectral scanner for several resource objectives. The deployment coincided with the summer low, steady-flow $(8,000 \mathrm{cfs})$ experiment conducted during 2000. During this low-flow experiment water levels were low, which provided ideal conditions for mapping near-shore, warm-water areas that are conducive to fish habitation. Deployment was scheduled for June, 2000 but was delayed by contracting until late July. This monsoonal time period caused days of grounded flights until clear-sky conditions occurred, but that was anticipated in the contract. In this study, we examine these data to determine the capability of the calibrated TIR data to (1) rapidly map warm-water fish habitats over large areas and (2) detect particular cultural resources that may present thermal anomalies, e.g., natural springs and buried archaeological structures. The results of our investigations are the subject of this report.

\section{Image Data and Study Area}

During the first year of the GCMRC remote sensing initiative, several remote-sensing databases were acquired that cover a range of sensor technologies and costs from scanned photographic CIR and digital CCD CIR data (both costing \$225/line km) to multispectral scanner data (costing \$620/line km). Only the multispectral scanner data provided thermal-infrared imagery. The multispectral data were acquired at 1:30PM on July 25, 2000 using the Advanced Thematic Mapper (Daedalus 1268 ATM) sensor between river mile 30 and river mile 74 (river miles in the Grand Canyon are referenced to Lees Ferry, Arizona). The portion of the Colorado River that was imaged by the ATM sensor is depicted on Figure 1. The time of our data acquisition coincided with the time of day that has been determined to be optimal for acquisition of thermal-infrared data, which is approximately 1:30PM local time, near the time of maximum solar heating (Price, 1977). The ATM sensor collected data in 12 channels at a spatial resolution of $100 \mathrm{~cm}$. The wavelength bands for the ATM channels are listed in Table 1. The signal-tonoise ratio (SNR) for each ATM channel (Table 1) was determined using the method of Gao (1993). A few of the ATM channels were not used in this study: channel 1 was too noisy (as indicated by its very low SNR ratio); channel 11 (the low-gain, thermal-infrared band) was mostly saturated due to its low gain state and the very high surface and ambient-air temperatures in the canyon during July. The ATM data were provided georectified in a UTM map projection (WGS84 datum) with a positional accuracy of 2-3 
meters.

Table 1. ATM band wavelength ranges and calculated signal-to-noise ratios.

\begin{tabular}{|c|c|c|r|}
\hline $\begin{array}{c}\text { Band } \\
\text { Number }\end{array}$ & Wavelength Region & $\begin{array}{c}\text { Wavelength } \\
\text { Range } \\
\text { (micrometers) }\end{array}$ & $\begin{array}{c}\text { Signal/Noise } \\
\text { Ratio } \\
\text { (SNR) }\end{array}$ \\
\hline 1 & Blue & $0.42-0.44$ & 9.9 \\
\hline 2 & Blue & $0.46-0.51$ & 76.8 \\
\hline 3 & Green & $0.52-0.59$ & 110.2 \\
\hline 4 & Green/Red & $0.59-0.62$ & 129.6 \\
\hline 5 & Red & $0.62-0.67$ & 142.2 \\
\hline 6 & Red/Near-infrared & $0.67-0.72$ & 134.1 \\
\hline 7 & Near-infrared & $0.73-0.85$ & 140.1 \\
\hline 8 & Near-infrared & $0.84-0.97$ & 21.2 \\
\hline 9 & Short-wave infrared & $1.59-1.79$ & 30.0 \\
\hline 10 & Short-wave infrared & $2.10-2.40$ & 16.4 \\
\hline 11 & Thermal infrared (low gain) & $8.28-10.67$ & 21.9 \\
\hline 12 & Thermal infrared (high gain) & $8.28-10.67$ & \\
\hline
\end{tabular}

\section{Data Analysis}

\section{Calibration of Visible-to-Short-wave Infrared Data to Ground Reflectance}

The recorded digital values for the nonthermal channels from the Bechtel ATM sensor were converted to ground reflectance using the empirical line method (Conel et al., 1987; Farrand et al., 1994). This method correlates recorded band digital values to known band reflectance values of surface targets. In June, 2000 we conducted field spectral surveys of various geologic and vegetation materials at many locations within river mile 30 and 74 using an Analytical Spectral Devices (ASD) field spectroradiometer and a Spectralon standard. For image calibration we used the brightest and darkest materials within the flight line. Bright surface targets consisted of large, uniform sand bar deposits. The spectral reflectance of the sand bar surfaces at various locations within the Colorado River corridor were quite consistent. Dark objects used in this analysis consisted of areas with the lowest and most uniform digital values, such as shadowed areas in deep side canyons and deep, clear water areas without sun glint. The observed digital numbers of the nine nonthermal ATM bands within such areas were consistent throughout this section of the river corridor. These dark-object values were assumed to represent a reflectance of $1 \%$ because few surfaces have no reflectance. Other surfaces (e.g., dense, closed-canopy tamarisk groves and mesquite groves) with intermediate reflectance values in some of the ATM band wavelengths were also used in order to better define the linear regression between recorded ATM band values and ground reflectance for some of the wavelength bands. Regression of corresponding ground reflectance values 
and recorded digital values within each ATM wavelength band produced gain and offset values for each ATM nonthermal band, which were then used to convert each ATM band's recorded digital values to surface reflectance. An example of this calibration is provided for one of the short-wave infrared ATM channels in Figure 2. This calibration procedure provided normal reflectance (albedo) values for each picture element within the ATM image swath, which were then used in the following analysis to derive temperature for each water picture element.

Further processing of the ATM data to obtain surface water temperature was confined to picture elements that only represented water in order to reduce processing time. We therefore prepared an image mask for water areas, which was used to remove picture elements of land. The water mask was produced using one of the short-wave infrared bands because there is essentially no water penetration within that wavelength region. Figure 3 shows the more abrupt decrease in reflectance for a short-wave infrared band compared with the more gradual decrease in reflectance in the visible and near-infrared wavelength bands provided by the ATM sensor. Some editing of the water mask was necessary using visible wavelength bands in order to remove land picture elements within shaded areas and include some water picture elements within backwater areas that were removed using a single digital-number value of the short-wave image as a water/land cutoff. The editing was very minor for the 44 river miles.

The ATM image data show scanline striping (noise) in certain locations that could not be removed because the image data were delivered orthorectified, which rotated the original horizontal scanlines to diagonal scanlines whose orientations change with changing river course (examples of this are shown in the section of mapping warm-water habitats). If the image data were delivered unrectified with horizontal scanlines, removal of the scanline noise would have been possible using a combination of high- and low-pass digital filters. The difference between adjacent image stripes in the water is generally only a single digital number ( or $0.3^{\circ} \mathrm{C}$ ). This effect can be decreased by using a gain value that produces $0.1^{\circ} \mathrm{C}$ per digital number, which is the detection level advertised for the ATM sensor. The gain setting used for ATM band 12 produced a temperature range of $1{ }^{\circ} \mathrm{C}$ to $83^{\circ} \mathrm{C}$. This range could be reduced by a factor of three and still capture the temperature range of the water and give $0.1{ }^{\circ} \mathrm{C}$ intervals for each digital number in the TIR image.

\section{Conversion of ATM TIR Data to Water Temperature}

Radiance leaving the Earth's surface can be either reflected or emitted energy or a combination of both types. Within visible to short-wave regions reflected energy dominates and within the thermalinfrared region emitted energy dominates, but within the mid-wave infrared region (3-5 $\mu \mathrm{m})$ both forms contribute to the radiance recorded by a sensor. The general equation that describes recorded energy from the surface is as follows:

$$
L_{\lambda}^{T}=\rho_{\lambda} \cdot \tau_{\lambda} \cdot \frac{L_{\lambda}^{V I S / S W I R}}{\pi}+\varepsilon_{\lambda} \cdot \tau_{\lambda} \cdot \frac{L_{\lambda}^{T I R}}{\pi}+L_{\lambda}^{A}
$$

where $\mathrm{L}^{\mathrm{T}}$ is total radiance, $\mathrm{L}^{\mathrm{VIS} / \mathrm{SWIR}}$ is radiance from the visible to short-wave infrared region, $\mathrm{L}^{\mathrm{TIR}}$ is radiance from the thermal-infrared region, $\mathrm{L}^{\mathrm{A}}$ is solar radiance scattered by the atmosphere to the detector with no surface interaction (also known as haze), $\lambda$ is wavelength, $\rho$ is reflectivity, $\varepsilon$ is emissivity, $\tau$ is atmospheric transmissivity. If radiance is normalized by the incident solar flux (irradiance), the resulting 
value is referred to as reflectance for the reflected part of the equation and emittance for the emitted part of the equation. The visible, near-infrared, and short-wave infrared bands provided by the ATM sensor were converted to reflectance by the empirical-line calibration technique that was previously described. This technique also removes atmospheric scattering. The ATM TIR band recorded only emitted radiance in the 8.3-10.7 $\mu \mathrm{m}$ region. Thus, the TIR radiance values can be represented as follows:

$$
L_{\lambda}^{\text {TIRrecorded }}=\varepsilon_{\lambda} \cdot \tau_{\lambda} \cdot \frac{L_{\lambda}^{\text {TIRactual }}}{\pi}
$$

According to Kirchoff's Law, $\varepsilon=1.0-\rho$, and the above equation can be restated as follows:

$$
L_{\lambda}^{\text {TIRrecorded }}=\left(1-\rho_{\lambda}\right) \cdot \tau_{\lambda} \cdot \frac{L_{\lambda}^{\text {TIRactual }}}{\pi}
$$

Thus, our measured reflectance data can be used to estimate water emissivity for each water picture element. The reflectance in the water was anomalously high at riffles due to sun glint from riffle waves where wave surface angles matched that of the solar incidence angle. In order to distinguish glint from sediment-laden water reflectance, we used the short-wave infrared bands, which do not penetrate water, to determine where glint occurred. At these locations water reflectance values from nearby water that had no glint were used for the picture elements that did show glint. [Salisbury and D'Aria (1992) measured the emissivity for fresh water and found it to be 0.990. They found that suspended quartz sediment decreased water emissivity to only 0.988.] The actual radiance value $\left(\mathrm{L}_{\lambda}{ }^{\text {TIRactual }}\right)$ can also be expressed using Planck's black body radiance at a temperature $\mathrm{T}$ by the following expression:

$$
L_{\lambda}^{\text {TIRrecorded }}=\left(1-\rho_{\lambda}\right) \cdot \tau_{\lambda} \cdot \frac{C_{1}}{\pi \lambda^{5}\left(e^{C_{2} / T \lambda_{-} 1}\right)}
$$

where $C_{1}$ and $C_{2}$ are thermal constants equal to $3.7415 \bullet 10^{4} \mathrm{~W} / \mathrm{cm}^{2} / \mu \mathrm{m}^{4}$ and $1.4388 \bullet 10^{4} \mu \mathrm{m} \mathrm{K}$, respectively. Radiance is expressed in terms of $\mathrm{W} / \mathrm{cm}^{2} / \mu \mathrm{m}$. The overflight with the ATM sensor took place over a 20 minute interval for the entire 44 river miles. In this analysis we ignored possible changes in atmospheric transmissivity during this short period and assumed the transmissivity was similar within that river segment during the overflight. The ATM data were delivered as 8-bit digital numbers; the temperatures set for the digital numbers 0 and 255 allow the following conversion between recorded digital number and temperature, assuming an emissivity of one.

$$
\mathrm{T}(\mathrm{K})=0.321 \bullet(\text { digital number })+1.021+273
$$

This relation shows that the thermal-infrared data could detect temperature differences of $0.32^{\circ}$ or more. Bechtel assumed that the emissivity at each picture element was one. Therefore, the temperature from the above equation was used to calculate the radiance recorded by the TIR channel using the following relation. 


$$
L_{\lambda}^{\text {TIRrecorded }}=\frac{C_{1}}{\pi \lambda^{5}\left(e^{\left.C_{2} / T \lambda-1\right)}\right.}
$$

Using each picture element's calculated TIR radiance value and measured reflectance value in the water, which was derived from the ATM visible and near-infrared bands, we estimated each picture element's emissivity value using the Kirchoff Law and derived each picture element's measured temperature in the water using the following equation.

$$
T_{\text {radiant }}\left({ }^{\circ} C\right)=\frac{C_{2}}{\lambda \ln \left[1+\frac{\varepsilon_{\lambda} C_{1}}{L_{\lambda}^{\text {TIRrecorded }} \pi \lambda^{5}}\right]}-273
$$

The temperatures recorded by the ATM sensor are radiant temperatures at the surface of the water. In order to relate these recorded values to kinetic temperatures, which are measured by water gaging stations, we acquired the gaging station temperature data during the time of the overflight (shown in Figure 4) and interpolated these values at ten-mile increments within the region of the overflight to provide "ground-truth" temperatures for calibration. We then obtained the average airborne surface water temperature at the same ten-mile locations, plus the Little Colorado River gaging station, and determined by linear-regression analysis, the equation that converted our observed radiant temperatures to water kinetic temperatures (shown in Figure 5). This resulted in the following relation:

$$
T_{\text {kinetic }}\left({ }^{\circ} \mathrm{C}\right)=0.5926 \cdot\left(T_{\text {radiant }}\right)+8.63^{\circ} \mathrm{C}
$$

\section{Improved Rectification of the ATM Image Data}

The ATM data were delivered georectified in UTM map projection (WGS84 datum) using GPS data and assuming a constant elevation for a scanline equal to that of the water elevation. Thus, the locational error in the georectified data increases from the river to the (up-slope) ends of each scanline. In an attempt to improve the registration for higher elevation land areas, the ATM image data were rectified using the Emerge color-infrared image database that was acquired in September, 2000 and that was provided as an orthorectified database with a positional accuracy of about six meters. At the time of this analysis, there was no alternative orthorectified image base. As expected registration RMS errors increased dramatically toward both sides of the flight-line swath. The rectified surface water temperature map is shown in Figure 6 for the entire 44 river miles acquired by the ATM instrument. Specific areas will now be examined, whose locations are indicated on Figure 6, in terms of mapping warm backwaters along this 34-mile segment of the Colorado River.

\section{Mapping Warm Backwaters}

One of the main concerns of the GCMRC biologic resource program is the restoration and preservation of native fish species in the Grand Canyon, especially the Humpback Chub whose populations are relatively low due to unnatural low-flow regimes and cold tailwater releases produced by the Glen Canyon Dam. The Chub prefer backwaters that are warm $\left(18-22^{\circ} \mathrm{C}\right)$, turbid, and sheltered, such as return-current channels, shoreline embayments, and the mouths of tributaries. Once airborne TIR data 
are calibrated to reflect true surface water temperature, the locations of near-shore pockets of warm water should easily be detected and mapped using a temperature threshold for fish habitats. We now present examples of some of the warm backwater areas within the river coverage shown by the ATM data.

Figure 7a shows a shoreline embayment at river mile 34 where surface water temperatures are about $4{ }^{\circ} \mathrm{C}$ warmer than the main stem (Figure $7 \mathrm{~b}$ ). The airborne temperature profile, which coincides with the reflectance profile shown in Figure 3, shows that the land/water interface is even more pronounced in the TIR data than in the short-wave infrared (SWIR) data. In this embayment, only the very near-shore water temperatures exceed $18^{\circ} \mathrm{C}$ because the embayment is relatively small.

The mouth of Tatahatsu Wash shows a very gradual increase in temperature toward shore, rising about $10{ }^{\circ} \mathrm{C}$ above the main stem to temperatures near $23{ }^{\circ} \mathrm{C}$ near land (Figure 8 ). The TIR temperature profile shown in Figure 8 does not include land. The debris fan produced by the tributary shelters the backwaters from the colder main-stem waters. North of President Harding Rapids (Figure 9a) are two reattachment eddy bars; the larger, northern bar produced a large backwater area where temperatures average $17^{\circ} \mathrm{C}$ and rise to $20-23{ }^{\circ} \mathrm{C}$ at its shallowest extreme (Figure $9 \mathrm{~b}$ ). This area also shows one of the most pronounced examples of scan-line noise in the main stem.

Because of the low-flow (8,000 cfs) conditions during data acquisition, some backwater entrants were cut off from the mainstem by emergent sandbars. One such case is seen at river mile 50.2 (Figure 10a), where waveforms are visible on the surface of the sandbar and where isolated, shallow backwater areas exist that have temperatures in excess of $25^{\circ} \mathrm{C}$ (Figure 10b). Another example occurs south of Anatubi Canyon at river mile 58 (Figure 11a). Here, as at river mile 50.2, waveforms are visible on the surfaces of emergent sandbars on river right. The downstream entrant of the sandbar's backwater channel has been cut off from the mainstem due to the low-flow conditions, resulting in an isolated pocket of warm, shallow water whose temperatures exceed $25^{\circ} \mathrm{C}$ (Figure 11b).

Tributaries not only contribute sediment to the mainstem of the Colorado River, but they also provide a source for warm-water fish habitats. Both of these processes are visible at the confluence of the Little Colorado River with the mainstem of the Colorado River at river mile 61.5 (Figure 12a). The CIR image of this area shows the compositional differences between the two Little Colorado River channels that lead to the mainstem. The warming of the mainstem by the Little Colorado River, locally and downstream along river left, is shown in the TIR temperature map (Figure 12b).

We attempted ground-truth verification of our airborne-TIR calibration procedure by comparing the airborne TIR temperature data to temperature data collected with thermistors near the time of our airborne data acquisition. The thermistor string was deployed the day before the overflight at river mile 64. The exact location of the thermistor string was not obtained in the field and therefore had to be visually estimated using CIR image data. Figure 13a shows the approximate location of the thermistor string (profile C-C'). Figure 13b compares the temperatures recorded at the five thermistors with the temperatures observed in the airborne TIR data at distances from shore that corresponded with the locations of the thermistors. Except for the coincidence of the farthest thermistor in the mainstem, the airborne temperature data are consistently $2{ }^{\circ} \mathrm{C}$ higher than temperatures recorded by the thermistors. The two data collections were planned to coincide, but severe cloud cover on July $24^{\text {th }}$ precluded overflights. The cloud cover could have also produced less solar heating of this near-shore area on July $24^{\text {th }}$, which may account for the temperature offset between the airborne and ground data.

The shoreline embayment north of Tanner Rapid at river mile 68 provides another example of 
visible surface morphology on shallow-water portions of an eddy sandbar (Figure 14a). The eddy bar formed a very long $\left(100 \mathrm{~m}\right.$ ), curvilinear backwater channel whose temperatures are $20-23{ }^{\circ} \mathrm{C}$ (Figure $14 \mathrm{~b})$. In this particular case, the extreme end of the channel is not the warmest water in the channel. The depth of the water at the end of the channel may be deeper than at the middle of the channel.

All of the examples provided in this section suggest that it would be easy to construct a thematic map of the warm-water areas that may be conducive to fish habitation. This could be accomplished for a large portion or even the entire corridor of the Grand Canyon using a simple temperature threshold. The threshold value would obviously be higher than the mainstem temperature and close to the temperature that has been found conducive to fish habitation $\left(18^{\circ} \mathrm{C}\right)$. Thresholding would not be affected by the striping observed in parts of the mainstem data because the striping is limited to the lower mainstem surface water temperatures that are closer to the signal-to-noise limit of these data. The calibration used in this study was controlled mainly by the singular high temperature datum obtained at the Little Colorado River (Figure 5). A better calibration procedure for the airborne TIR data would use groundtruth temperatures that cover the temperature range of interest and at regular intervals within that temperature range. This would require reliable locations for the ground-truth measurements throughout the period of possible airborne data collection.

\section{Detection of Archaeological Structures}

Many of the archaeological structures within the Grand Canyon are subject to degradation by human foraging and by natural erosion. Because of this, one of the priorities of the cultural resource program is the development of a method to monitor these processes and their effects and to develop techniques to mitigate the processes. TIR and radar data have been used over the past two decades to find archaeological structures (e.g., McAleer, 1988), although many discoveries have been serendipitous. The capability of these data for this purpose depends on the setting of the archaeological site, i.e., the structures need to be unobstructed from view by solid objects and the structures need to have thermal or electrical properties different from their surroundings. Some of the archaeological sites within the Grand Canyon occur on or within alluvial deposits that are not covered by vegetation. The masonry or stone structures should have thermal properties different from those of the unconsolidated alluvium on or in which the structures occur and, therefore, such sites should be detected by TIR imagery given the correct acquisition conditions.

ATM multispectral data (which included thermal-infrared imagery) were collected to examine the capability of thermal-infrared imagery to address several GCMRC program requirements; one requirement being the detection of partly or totally obscured structures and possibly the monitoring effects of natural processes on these structures. In order to evaluate the capability of the daytime ATM TIR data for this cultural requirement, we searched for archaeological sites that had a geologic setting that would be conducive to the detection of manmade rock or masonry structures. We used 11-cm CIR image data that were collected during the same month as the ATM data to determine if known archaeological structures existed within the 500-m image swath provided by the ATM sensor. Examination of South Canyon, Anasazi Bridge, and Nankoweap sites showed that the ATM-image swath did not reach the elevated structures that occur in these areas. However, the ATM data do cover a part of the Unkar delta, which contains several structural sites. We located the archaeological structure sites using a published brochure that depicted their locations (Balsom, 1989) and using 11-cm CIR image data, which were orthorectified using an existing $18.5-\mathrm{cm}$ panchromatic orthophoto mosaic, to help identify their locations on the lower-resolution ATM data. The locations of nine sites that we located are shown on Figure 15. Of the nine sites, only five occur within the ATM image swath; these are shown in Figures 16 through 18. 
Unfortunately, the largest structural site (area 7 on Figure 15), which is in a setting most conducive for thermal-infrared detection, does not occur within the ATM image swath. It was difficult to locate the structure at area 5 (Figure 18) because the scanning process used to digitize the CIR film tended to saturate (over-expose) the bright alluvium that occurs at this site. As evidenced by the image of area 5 (Figure 18), it was difficult to overcome the saturation to show the structures at that site. Despite the saturation problem, we found the 11-cm CIR data to better depict the archaeological structures than 18.5$\mathrm{cm}$ panchromatic image data, which is due to the higher resolution of the CIR film and/or due to the better color contrast between different surface materials provided by CIR data.

We outlined the same five areas on the ATM image data that contain the archaeological structures shown in Figures 16-18 to determine if the structures were visible on the ATM image data at its $100-\mathrm{cm}$ resolution (Figure 19). Area 5 occurs at the extreme limit of the ATM image swath where rectification distorted the picture elements at the swath terminus. Examination of each ATM band image and many different three-band combinations of the nine nonthermal ATM bands showed no irrefutable evidence of the structures at these five sites. This observation suggested that the TIR data may not display the structures either, but TIR data commonly show features that are not visible in reflected wavelengths, even when the TIR data are acquired at lower spatial resolutions than the reflected-wavelength imagery. Thus, we proceeded to superpose the locations of these five structural sites onto the ATM TIR image (Figure 20), which is enlarged by a factor of two over that of the ATM CIR image (Figure 19) to show the limits of the data. Examination of the TIR image shows no thermal anomalies that uniquely correspond to any of the structures shown in Figures 16-18.

Materials that are solid, such as archaeological foundations and walls, have very different thermal properties than unconsolidated fine-grained materials, even if the two materials have the same mineral composition. This is the reason that TIR data can determine surface grain size. The masonry or rock structures at Unkar delta should present very different thermal properties than the surrounding unconsolidated alluvium. Thus, given appropriate thermal data, the structures should be distinct from the alluvium, but not the natural rocks that are scattered on the delta's surface. There are three attributes of thermal data to consider: (1) time of day for data acquisition, (2) spatial resolution of the data, and (3) temperature sensitivity of the data. Each of these factors will now be considered as to their relative impact on our TIR results.

The time of day for maximum solar heating (1:30 PM), when the ATM data were acquired, is also one of the two times in a 24-hour period when thermal contrast between geologic materials is minimal (the other time is 12 hours later at night), but thermal contrast between different water, vegetation, and geologic materials is maximized. Detection of the archaeological structures is an issue of discrimination between geologic materials. The optimal time of day for discrimination of geologic materials is either at sunrise or at sunset, when the intrinsic thermal properties of materials dominate their thermal signal, either by differential absorption of solar heat or by differential emission of stored solar heat (both controlled by a material's thermal inertia). Data acquisition an hour after sunset would provide better conditions for discrimination of these materials on the delta because directional (slope-induced) heating effects that add clutter to thermal infrared imagery will be removed from post-sunset data. Data acquisition using sensors that need to be flown below the canyon rim (to obtain adequate resolution) may be a real problem after sunset.

Spatial resolution is always a concern in remote sensing. One-meter image data is rather low resolution relative to previous optical image data that have been acquired by GCMRC. To demonstrate the effect of lower spatial resolution on the detection of archaeological structures using optical data, we 
degraded the resolution of the 11-cm CIR data to $100 \mathrm{~cm}$ using a digital spatial filter. Figure 21 compares the 11-cm and the filtered 100-cm CIR images for structural area 1. The archaeological structures cannot be uniquely defined in 100-cm resolution image. The 100-cm resolution CIR image for area 2 shows some evidence of a structure at the site, but interpretation of the structure's outline on this low-resolution image would produce a very different set of structure outlines than those that actually exist at the site (Figure 22). Only at area 3 does the lower resolution image show the true outline of the existing structure. Obviously, the detection of subtle changes in the archaeological structures using optical data would require even higher resolution than $11 \mathrm{~cm}$. Although higher spatial resolution would certainly improve the chances for detection of the archaeological structures, that factor mostly provides better spatial delineation of geometric features, but it does not improve thermal distinction between materials unless the scale of the features examined is far below the resolution of the TIR data. In our case, the structural walls are about one-third $(30 \mathrm{~cm})$ of a picture element's spatial dimension. This difference in scale is not large enough to result in a total absence of thermal anomalies. Satellite TIR image data are commonly a factor of three lower in resolution than their accompanying reflected-wavelength band data, and the TIR data do detect linear thermal anomalies well below their spatial resolution. The effect of lower spatial resolution is to merge discrete thermal (and reflected) anomalies into fewer and larger anomalies. Although shape may be lost, the anomaly should still be visible if the thermal data could actually detect an anomaly.

Detection of thermal differences, whether imaged at night or during daylight hours, is largely dependent upon the sensitivity of the thermal detector. Nash (1985) found that a sensitivity of $0.1{ }^{\circ} \mathrm{C}$ is necessary to detect geologic thermal anomalies. All thermal sensors provide sensitivities of $0.1^{\circ} \mathrm{C}$ for that very reason. The gain setting used to collect the ATM data produced a sensitivity of only $0.3{ }^{\circ} \mathrm{C}$, even though the thermal detector can obtain a sensitivity of $0.1^{\circ} \mathrm{C}$. It is most likely that the low sensitivity of the TIR data precluded detection of the thermal contrast between the archaeological structures and the alluvial materials on Unkar delta.

\section{Detection of Natural Springs}

Although the detection of natural springs is not a high priority for the cultural resource program, we examined the daytime ATM TIR data to determine if springs could be detected with 1-m, daytime TIR data. The time of our overflight (1:30PM) coincided with the time of maximum solar heating of the surface. Because of this, temperature differences between wet and dry alluvium or rock at this time will be very small and difficult to detect. Detection is further complicated by shading on the canyon walls which can produce lower surface temperatures than sunlit surfaces and can therefore have temperatures that approach wet surfaces. Examination of the ATM TIR data show that only the large (high volume) springs are detected with daytime TIR (such as Vaseys Paradise and some tributaries) because they provide a larger volume (thicker layer) of water on the surface and are therefore cooler than the dry rock or alluvial surfaces. Examination of all areas containing faults did not reveal TIR anomalies along these wall fractures.

As stated previously, the detection of materials that have different thermal properties is best accomplished at times when either the solar source is turned on (sunrise) or turned off (sunset). It is at these two times when the intrinsic thermal differences between materials is best observed. This is also the reason that previous TIR (FLIR) studies have acquired airborne data at sunrise and sunset (Holroyd, 1995a,b). These studies did detect a number of possible natural springs, but were unable to verify their results due to poor locational information for the FLIR data. Detection of springs using post-sunset or pre-dawn TIR data does not require high spatial resolution because the thermal difference between the 
warmer spring water and the colder dry ground will be well above the signal-to-noise level of the detector and observed, even at 1-2 meter resolution. Ground resolution for such data will therefore be determined by the requirements dictated by the more subtle archaeological resources.

\section{Cost-benefit analysis}

With respect to mapping warm backwaters, the use of TIR data will not reduce the need for insitu water measurements because (1) periodic data on water quality are needed throughout the year and (2) the airborne TIR data need ground-truth information for calibration. Therefore, the use of TIR image data to provide an instantaneous, wide-area map of surface water temperature within the Grand Canyon will be an added expense that needs to be weighed against the need for such information. The cost for acquiring TIR with helicopter-mounted multispectral scanners is about $\$ 620 /$ line-km. The cost for TIR data acquisition and the benefit derived from the TIR data may reside fully on the biologic resource program because of possible limitations of daytime thermal-infrared data for cultural program requirements and the fact that data acquisition after sunset for cultural requirements may be prohibited by the National Park Service. However, the reflected-wavelength data that are also collected with the TIR data can be used to map riparian vegetation, which would reduce the financial impact of a single overflight. In addition, the use of airborne TIR may reduce the need for the periodic thermistor-string surveys that are currently performed at selected river reaches because airborne TIR data can map the backwater areas more efficiently. However, some ground-truth data in high-temperature waters would improve the accuracy of the airborne water-temperature maps. Thus, thermistor-string surveys may not be completely replaced by the airborne data. In addition, if backwater temperatures need to be monitored at various times within a year, then the annual cost for an airborne-TIR option will be excessive, considering the $\$ 276,000$ cost for a single canyon-wide $(445 \mathrm{~km})$ airborne survey.

\section{Conclusions and Recommendations}

Airborne thermal-infrared data were acquired at 100-cm resolution during maximum solar heating (at 1:30 PM) to investigate the capability of such data for mapping warm backwaters in addition to mapping archaeological structural sites and natural springs within the Grand Canyon. The thermal data were acquired at a low- and high-gain setting, but the low-gain state did not provide better data for land than the high-gain state and the low-gain state was set so low that water temperatures were not recorded. From our analyses of the high-gain TIR data for the three program protocols mentioned above we make the following observations and recommendations.

1. Airborne TIR data require ground-truth water-temperature data that cover the range of surface water temperatures of interest. These ground truth temperature data need to be collected with good locational accuracy. Given such ground-truth data, the procedure for calibration to surface water temperature is rather straightforward and provides an instantaneous map of surface water temperature for very large regions, which cannot be obtained by in-situ measurement methods.

2. For purposes of mapping surface water temperature, airborne TIR data should be collected (1) near the period of maximum solar heating (1:30 PM), (2) using a gain state that brackets the temperature range of the water areas and provides at least a sensitivity of $0.1{ }^{\circ} \mathrm{C}$, and (3) during periods of continuous clear sky conditions (near the summer solstice).

3. Detection of archaeological structures requires a thermal sensitivity of at least $0.1{ }^{\circ} \mathrm{C}$. Detection (mapping) of both archaelogical structures and natural springs would be better 
approached using TIR data collected after sunset, when the solar flux is eliminated and when the intrinsic thermal properties of materials control their thermal emissions. Sunrise is also such a period of time, but solar illumination of the river corridor in these early morning hours is very limited. Delineation of the archaeological structures would also be improved using data with spatial resolutions higher than $100 \mathrm{~cm}$. However, the detection of natural springs after sunset can and has been accomplished using low-resolution imagery (1-3 meters) because the spring waters spread from their source and present a large area and higher thermal contrast with the surrounding dry ground surface. Given the high priority for detection of change at archaeological sites, which is very subtle and cannot be adequately accomplished using 11-cm photography, pursuit of TIR for that purpose is not recommended. The cost for very high resolution TIR data cannot compete with the cost for high-resolution aerial photography.

4. Considering the cost for TIR data $(\$ 620 /$ line-km), periodic imaging of large segments of the Colorado River for temporal analyses is cost prohibitive. On the other hand, a helicoptermounted TIR sensor can acquire data at a rate of $80 \mathrm{~km} /$ hour, which means that the entire canyon system could be mapped within 3 days, assuming flights are restricted to a two-hour window centered on 1:30 PM. Alternatively, if only the first one-third $(160 \mathrm{~km})$ of the canyon system was required, this segment could be imaged using a helicopter system in a single two-hour flight day. The cost $(\$ 620 /$ line-km) may be reduced by selecting sensors that provide fewer reflectedwavelength bands, such as the SpectraView sensor operated by Airborne Data Systems. This sensor can acquire seven wavelength bands (three visible, a near-infrared, a short-wave infrared, a mid-wave infrared, and a thermal-infrared band) as 12-bit data at $25-\mathrm{cm}$ resolution with a $2048 \mathrm{X}$ 2048 CCD camera. Such data would be very useful for mapping riparian vegetation. Thus, that single data set would address two biologic resource requirements and would probably cost less than the 12-channel ATM data. 


\section{References Cited}

Balsom, J., 1989, Unkar Delta Guide, Grand Canyon Natural History Association.

Berlin, G. L., Ambler, J. R., Hevly, R. H., and Schaber, G. G., 1977, Identification of a Signagua agricultural field by aerial thermography, soil chemistry, pollen/plant analysis, and archaeology, American Antiquity 42, 588-600.

Berlin, G. L., Salas, D. E., and Geib, P. R., 1990, A prehistoric Signagua agricultural site in the ashfall zone of Sunset Crater, Arizona, J. Field Archaeology 17, 1-16.

Conel, J. E., Green, R. O., Vane, G., Bruegge, C. J., and Alley, R. E., 1987, AIS-2 radiometry and a comparison of methods for the recovery of ground reflectance, In Proc. $3^{\text {rd }}$ Airborne Imaging Spectrometer Data Analysis Workshop (G. Vane, Ed.), JPL Publication 87-30, Jet Propulsion Laboratory, Pasadena, Ca, pp. 18-47.

Eckhardt, D., 1998, Mapping temperatures of the Colorado and Little Colorado Rivers in the Grand Canyon using airborne thermal sensors, Bureau of Reclamation Technical Service Center Technical Memorandum 8260-98-11, 22 p.

Farrand, W. H., Singer, R. B., and Merenyi, E., 1994, Retrieval of apparent surface reflectance from AVIRIS data: A comparison of empirical line, radiative transfer, and spectral mixture methods: Remote Sens. Environ. 47, 311-321.

Gao, B-C., 1993, An operational method for estimating signal to noise ratios from data acquired with imaging spectrometers, Remote Sens. Environ. 43, 23-33.

Gillespie, A. R., and Kahle, A. B., 1977, Construction and interpretation of a digital thermal inertia image, Photog. Engr. and Remote Sensing 43, 983-1000.

Holroyd, E. W., 1995a, Thermal infrared (FLIR) mosaics of the Little Colorado River and FLIR instrumentation, Bureau of Reclamation Technical Service Center Technical Memorandum 8260-95-01, 34 p.

Holroyd, E. W., 1995b, Temperatures and warm springs along the Little Colorado River, Bureau of Reclamation Technical Service Center Technical Memorandum 8260-95-03, 7 p.

Johnson, J. R., Lucey, P. G., Horton, K. A., and Winter, E. M., 1998, Infrared measurements of pristine and disturbed soils 1. Spectral contrast differences between field and laboratory data, Remote Sens. Environ. 64, 34-46.

Kahle, A. B., and Alley, R. E., 1985, Calculation of thermal inertia from day-night measurements separated by days or weeks, Photog. Engr. and Remote Sensing 51, 73-75.

McAleer, N., 1988, Pixel archaeology, Discover, August Issue, 72-77.

McManus, J., Duck, R. W., and Anderson, J. M., 1999, The relative merits and limitations of thermal radiometric measurements in estuarine studies, Intern. J. Remote Sensing 20, 549-559. 
Nash, D. B., 1985, Detection of bedrock topography beneath a thin cover of alluvium using thermal remote sensing, Photog. Engr. and Remote Sensing 51, 77-88.

Price, J. C., 1977, Thermal inertia mapping: A new view of the Earth, J. Geophys. Res. 82, 2582-2590.

Salisbury, J. W., and D'Aria, D. M., 1992, Emissivity of terrestrial materials in the 8-14 $\mu \mathrm{m}$ atmospheric window, Remote Sens. Environ. 42, 83-106.

Schott, J. R., 1989, Image processing of thermal infrared images, Photog. Engr. and Remote Sens. 55, 1311-1321.

Watson, K., 1992a, Spectral ratio method for measuring emissivity, Remote Sens. Environ. 42, 113-116.

Watson, K., 1992b, Two-temperature method for measuring emissivity, Remote Sens. Environ. 42, 117121. 
Figure 1a. Index map showing swath coverage of ATM TIR image data

collected at 1:30PM on July 25,2000

between river mile 30 and 74 .

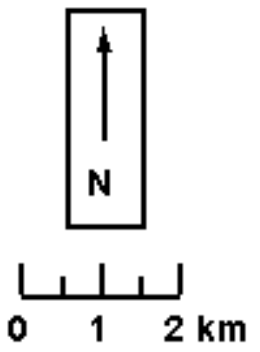

\section{Vaseys Paradise}

President Harding Rapid

Figures $3 \& 7$

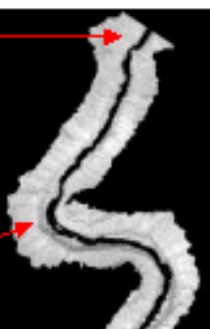

Figure 8

\section{RM 40}

Figure 8
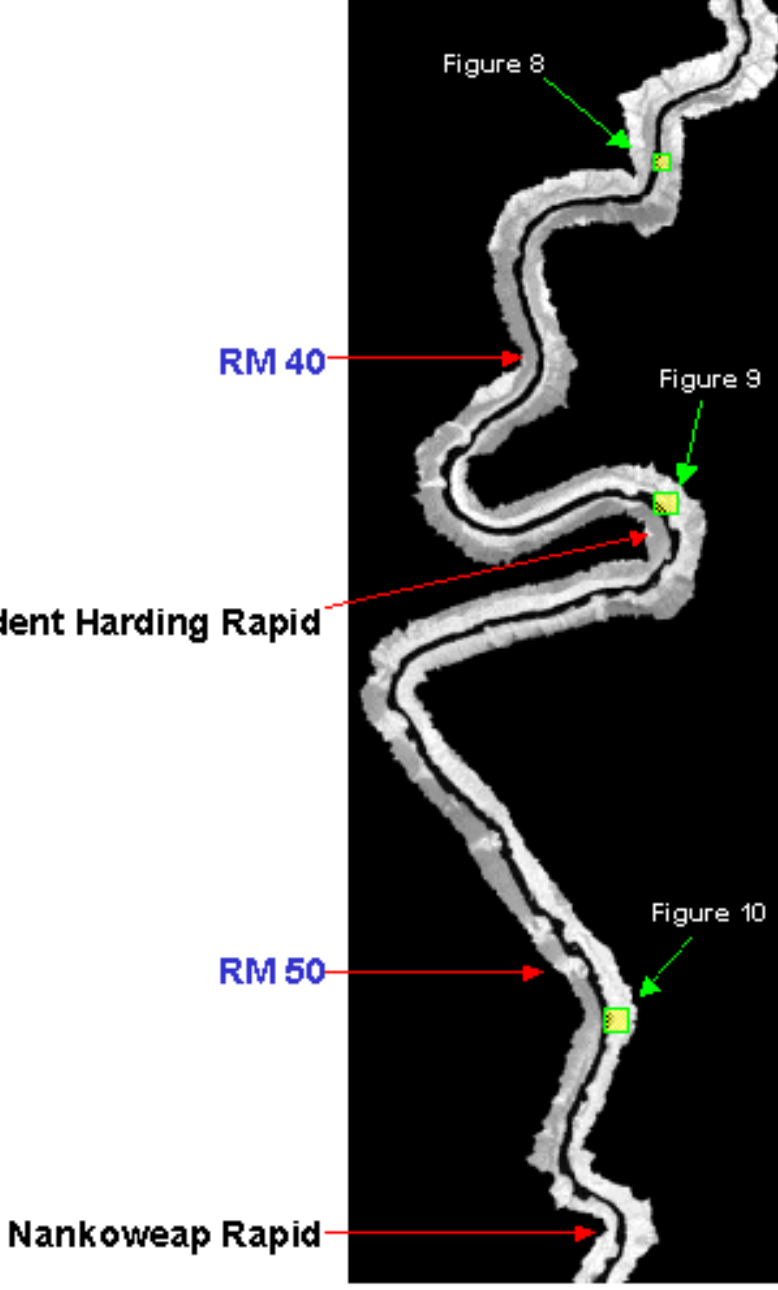


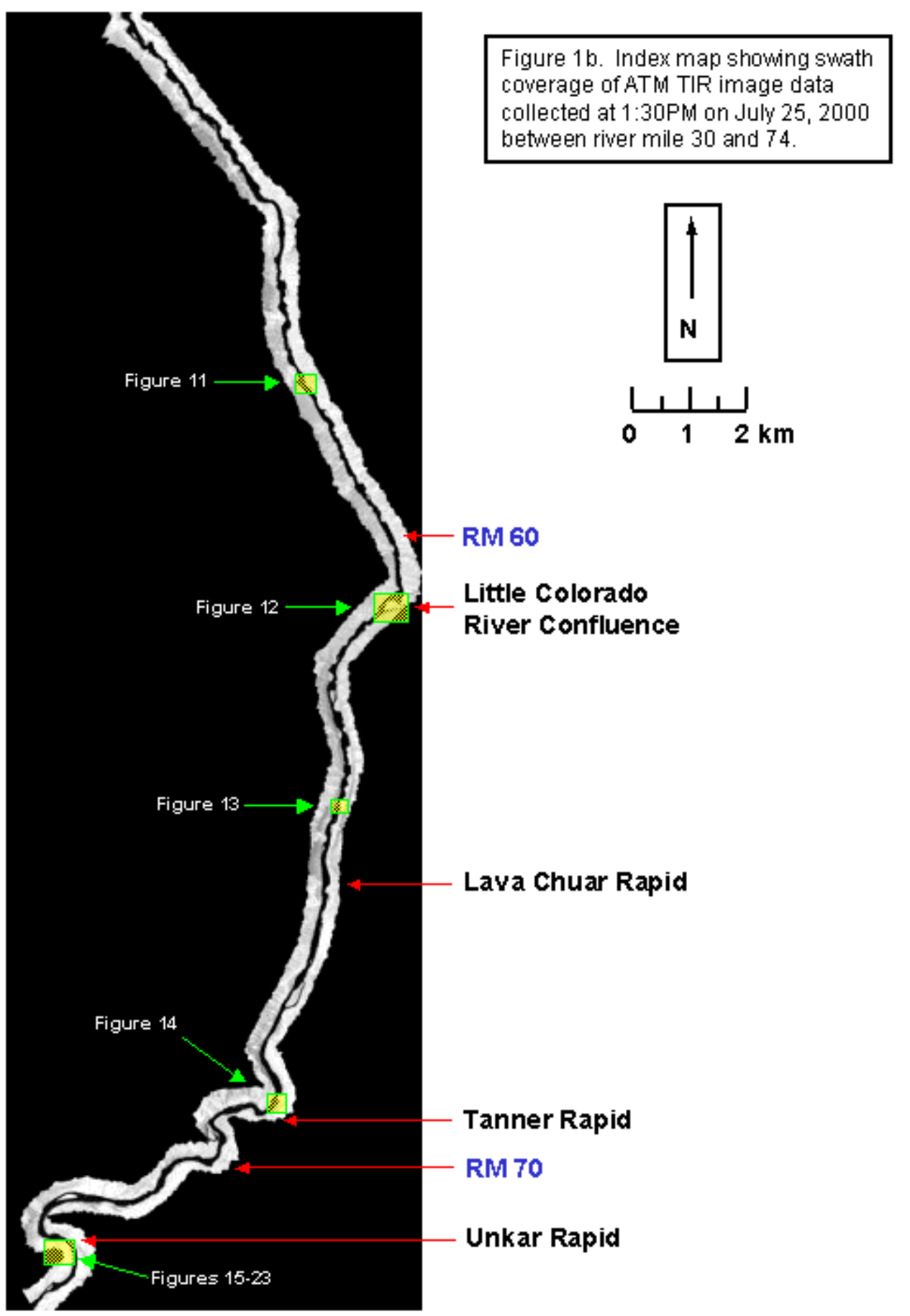




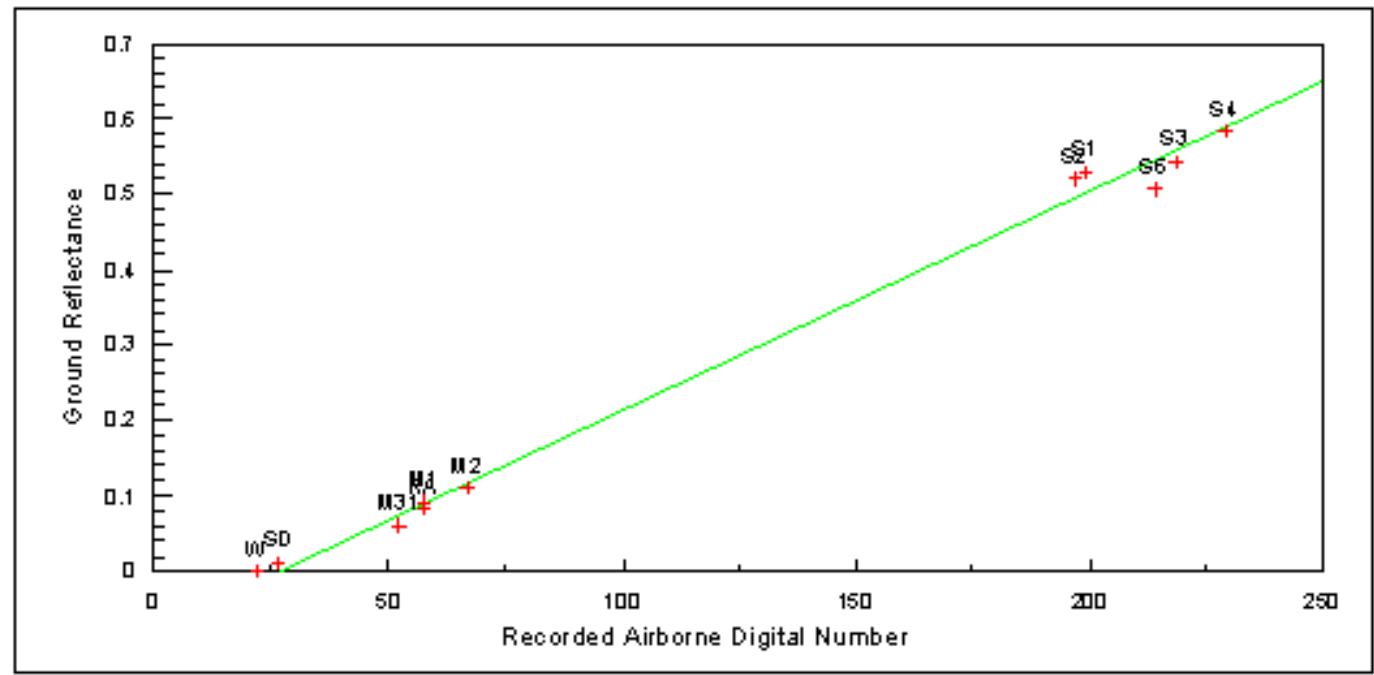

Figure 2. Relation between recorded digital number in ATM band 10 (short-wave infrared wavelength) and ground reflectance measured with a field spectroradiometer for different materials within the airborne ground track. Symbol-material correspondence is: $W$ (deep, clear water), SD (shadow), M (mesquite), RA (rush), and S (sand bars). Multiple sample sites of a particular material are given different numbers. 

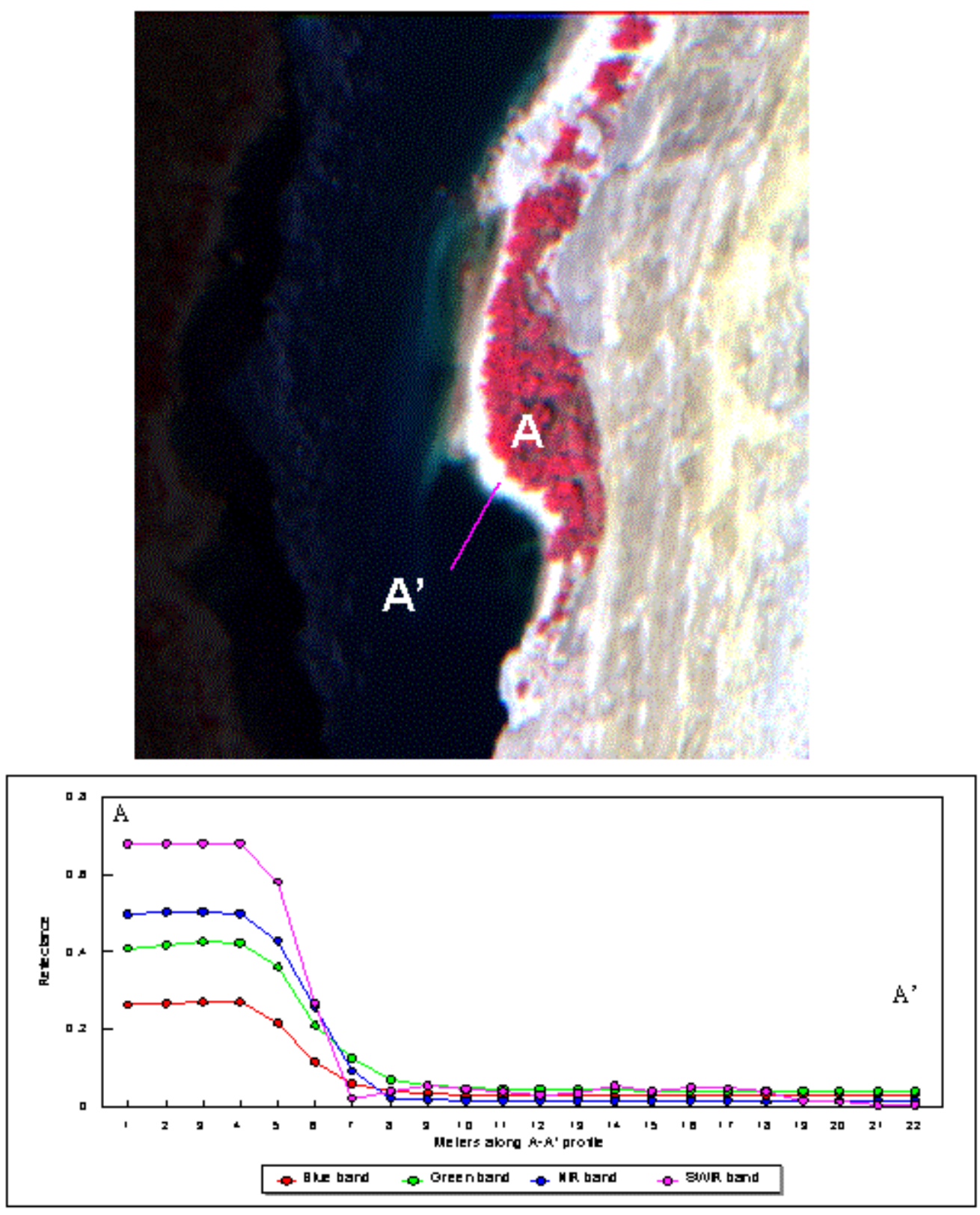

Figure 3. ATM CIR image of the left bank of the Colorado River at river mile 34 Although the water appears very distinct (black) in this image, the reflectance data along profile A-A' show that the land-water transition is less well defined in visible wavelength data than in short-wave infrared (SWIR) data. Image width is 210 meters. 


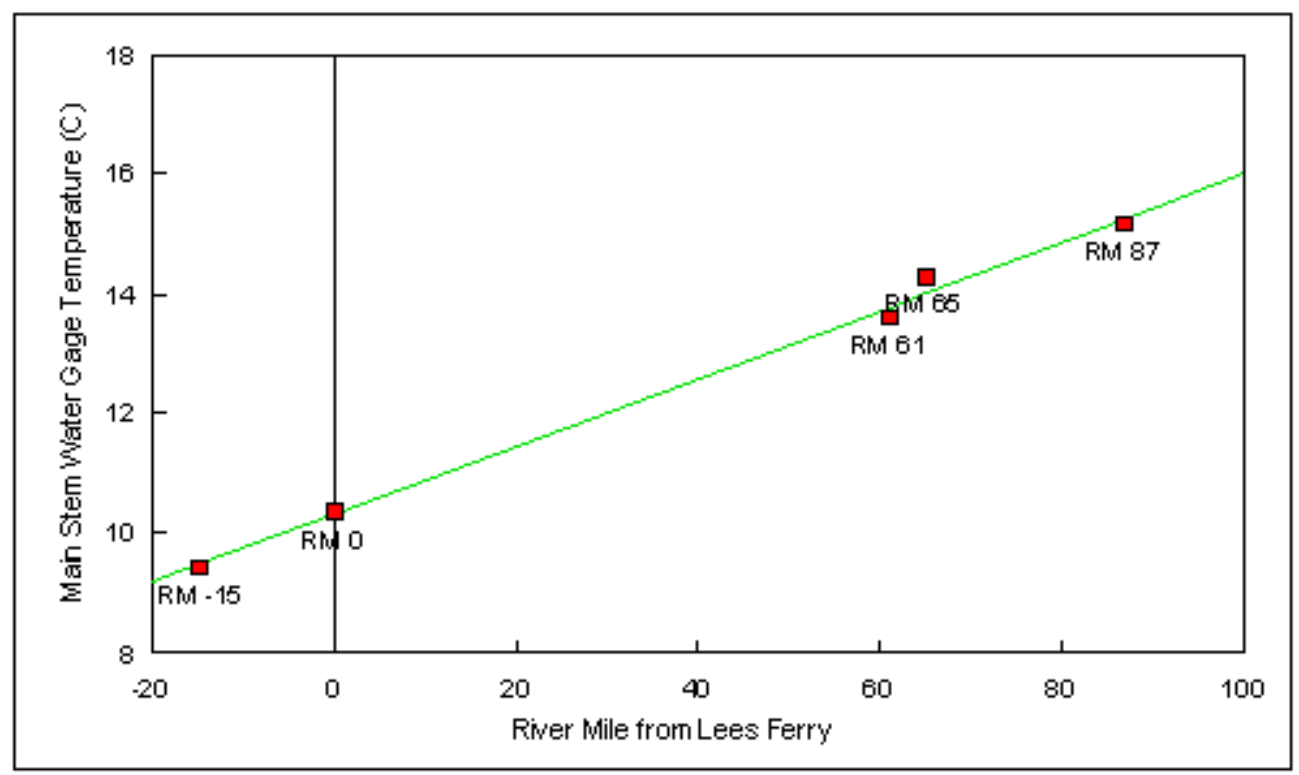

Figure 4. Main-stem water temperature $\left({ }^{\circ} \mathrm{C}\right)$ recorded by stream gaging stations within the northern one-third of the Grand Canyon near the time of the ATM overflight. 


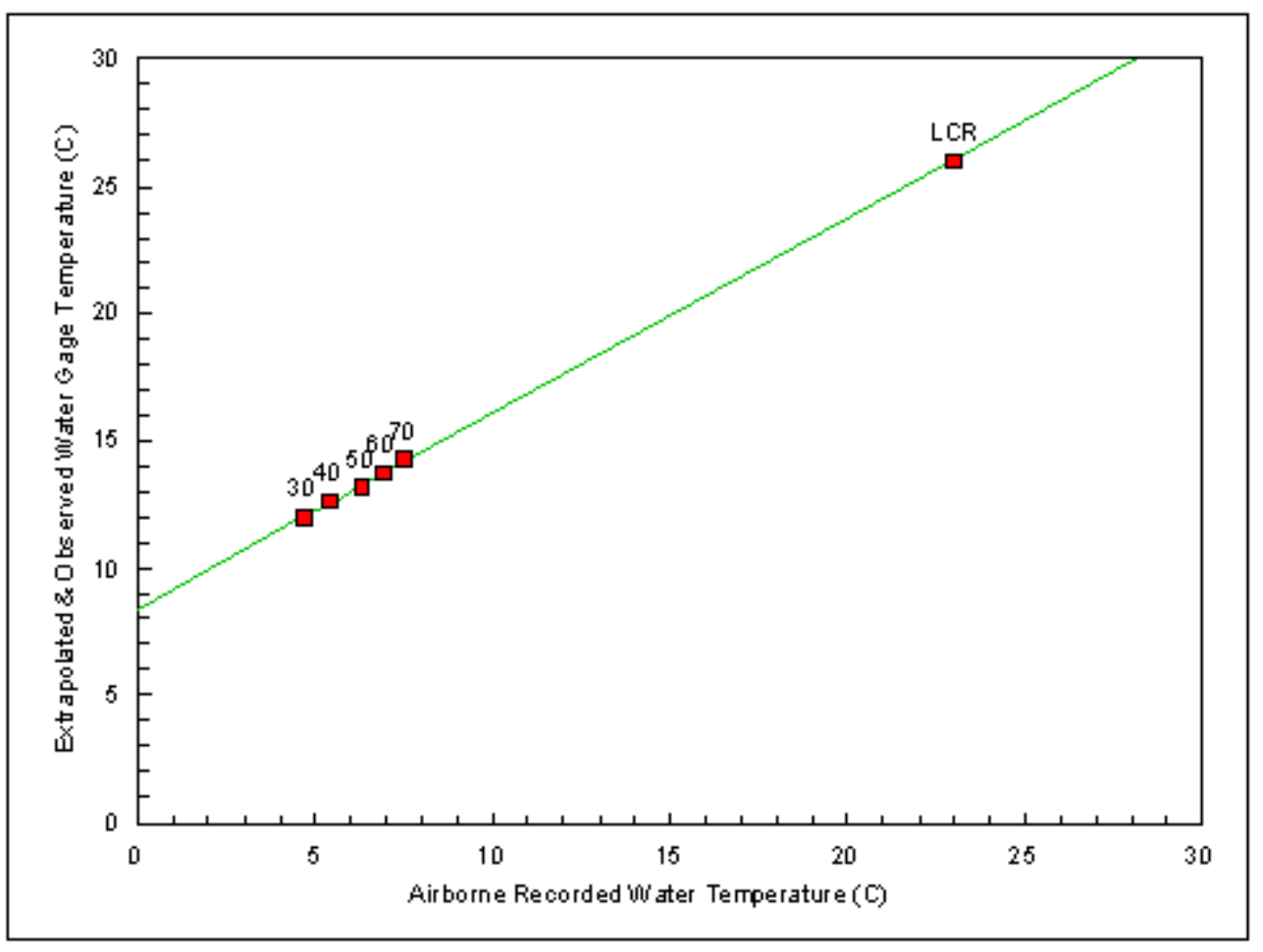

Figure 5. Relation between water temperature recoded by the airborne ATM TIR sensor and water temperature recorded at the Little Colorado River (LCR) gaining station and water temperatures obtained by extrapolation of main-stem water gage temperatures at 10 mile intervals between river mile 30 and 74 . 
Figure 6a. Calibrated, airborne water temperature map for river mile 30-74 at $1: 30 \mathrm{PM}$ on July 25,2000 . Land has been removed for examination of temperature dynamics.

TBMPERATURE ( $\left.{ }^{\circ} \mathrm{C}\right)$ COLOR SCALE

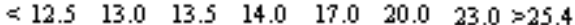
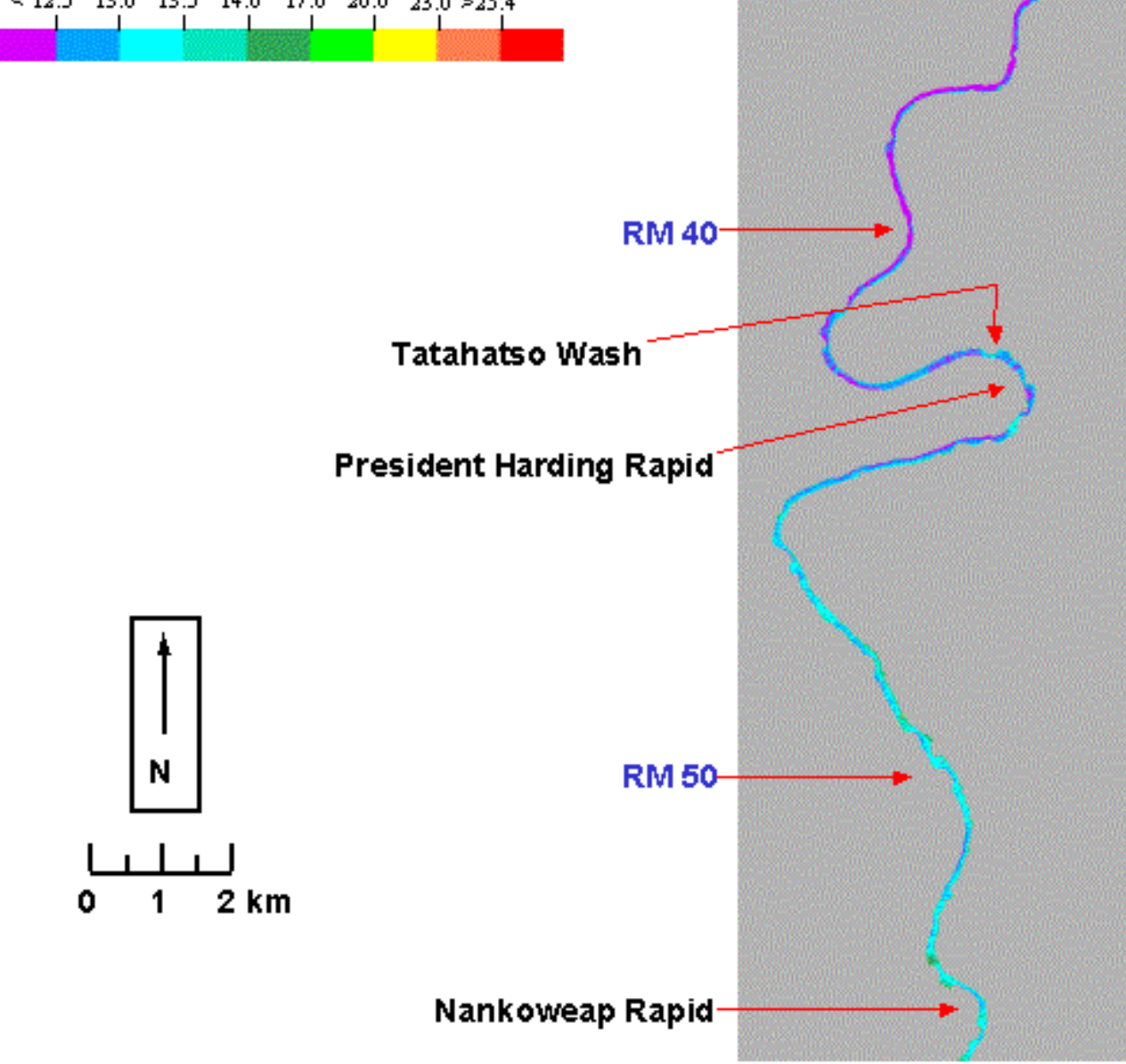


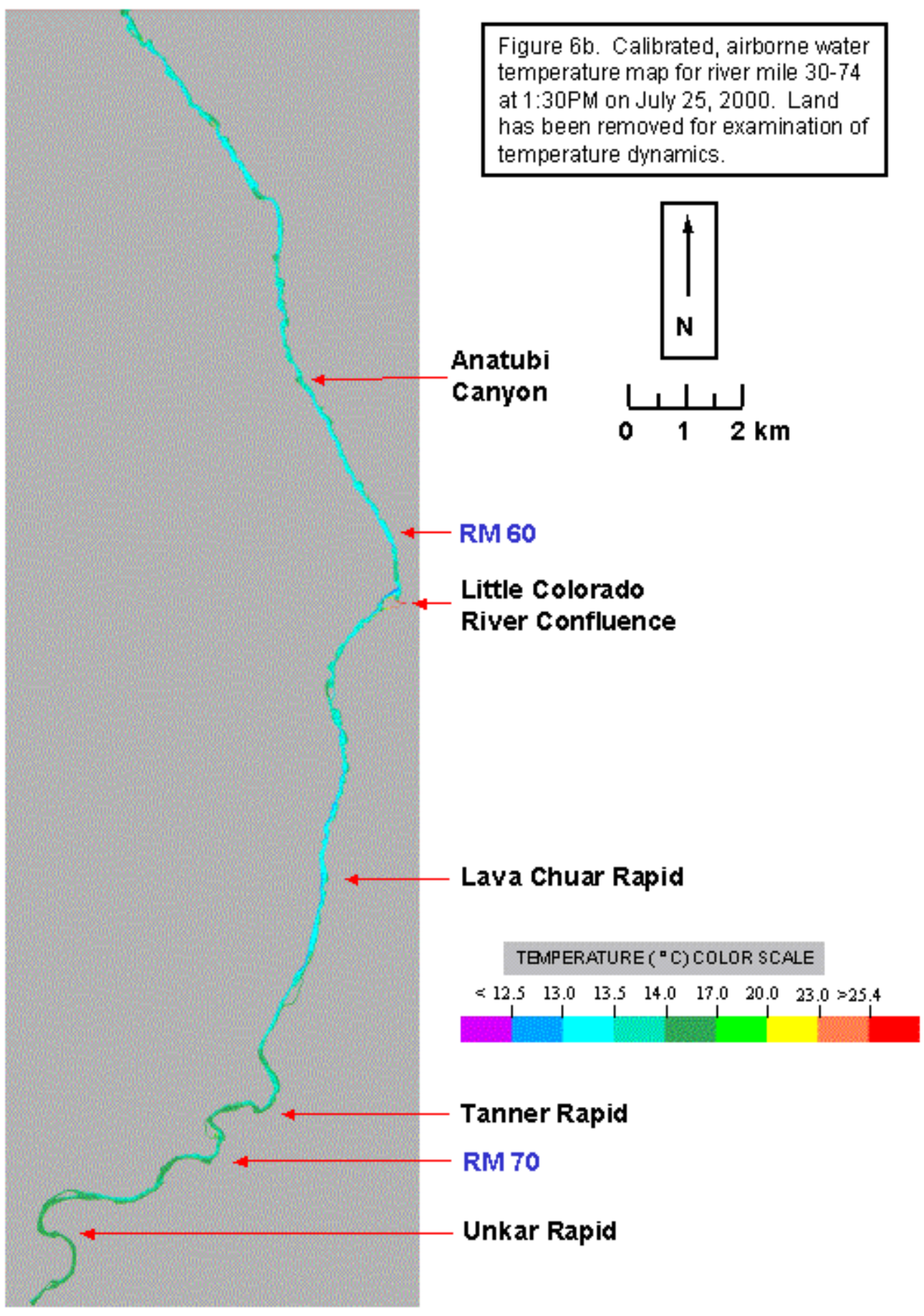




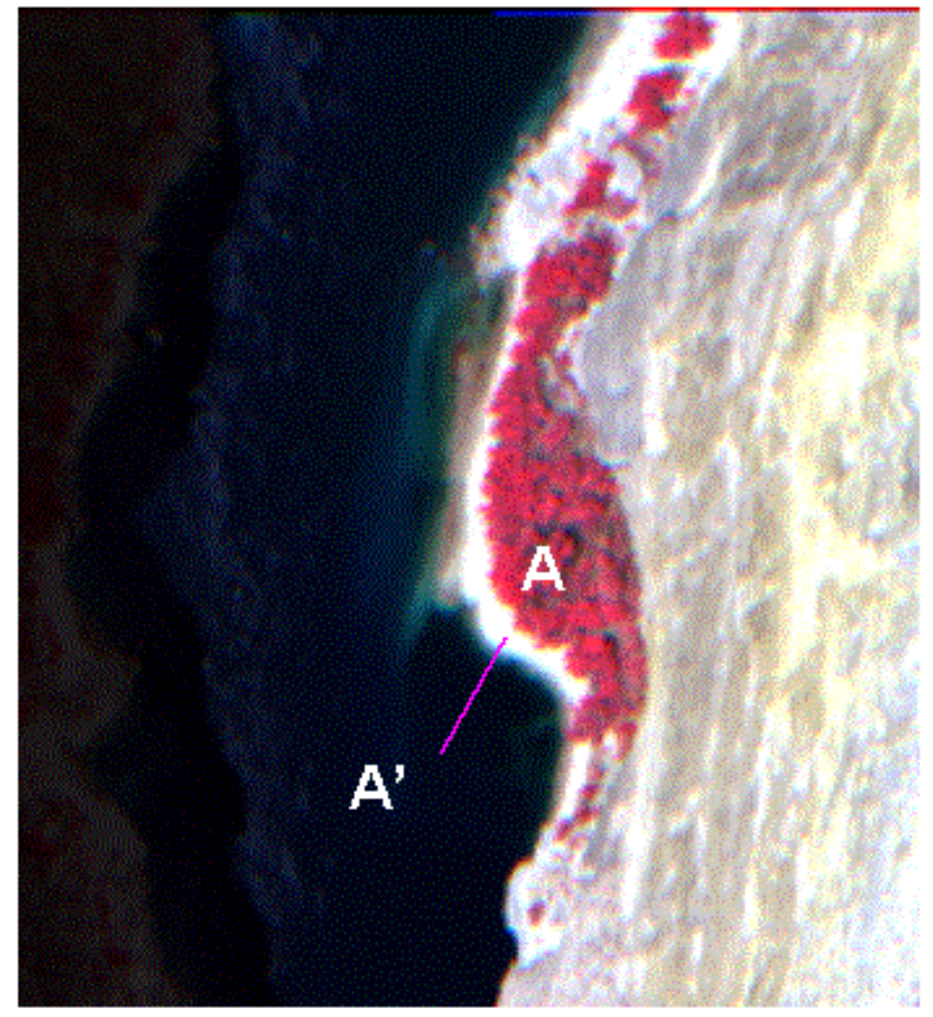

Figure $7 \mathrm{a}$. ATM CIR image showing a small shoreline embayment (eddy) on the left bank of the Colorado River at river mile 34. Profile A-A' coincides with the reflectance profile shown in Figure 3 and the temperature profile shown in Figure $7 \mathrm{~b}$.

Image width is 210 meters. 

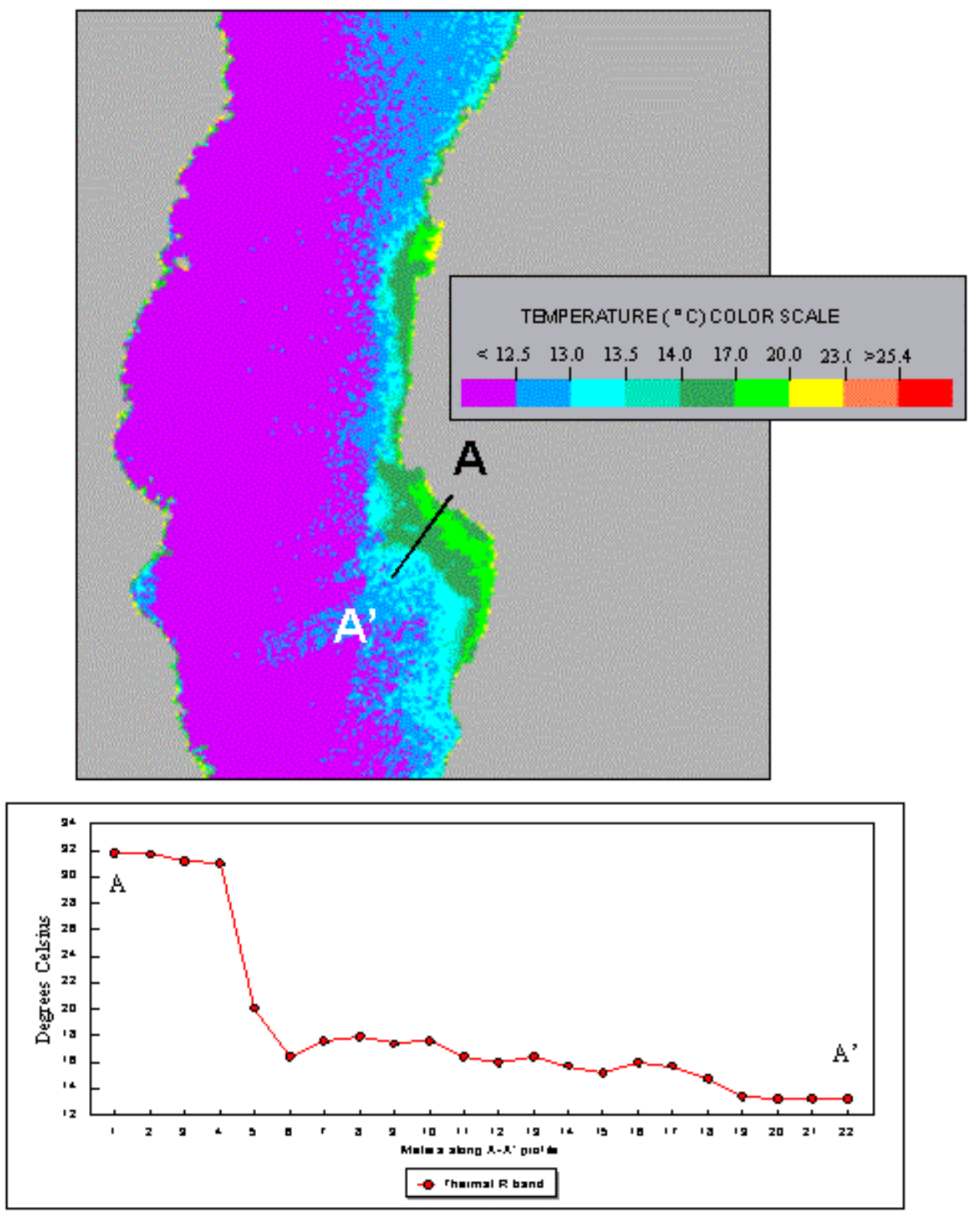

Figure $7 \mathrm{~b}$. Color-coded map of calibrated airbome-TIR water temperature (top) and the temperature profile along line A-A' (bottom) for the area depicted in Figure 7a. Land is gray, water colors correspond to temperature scale shown. 

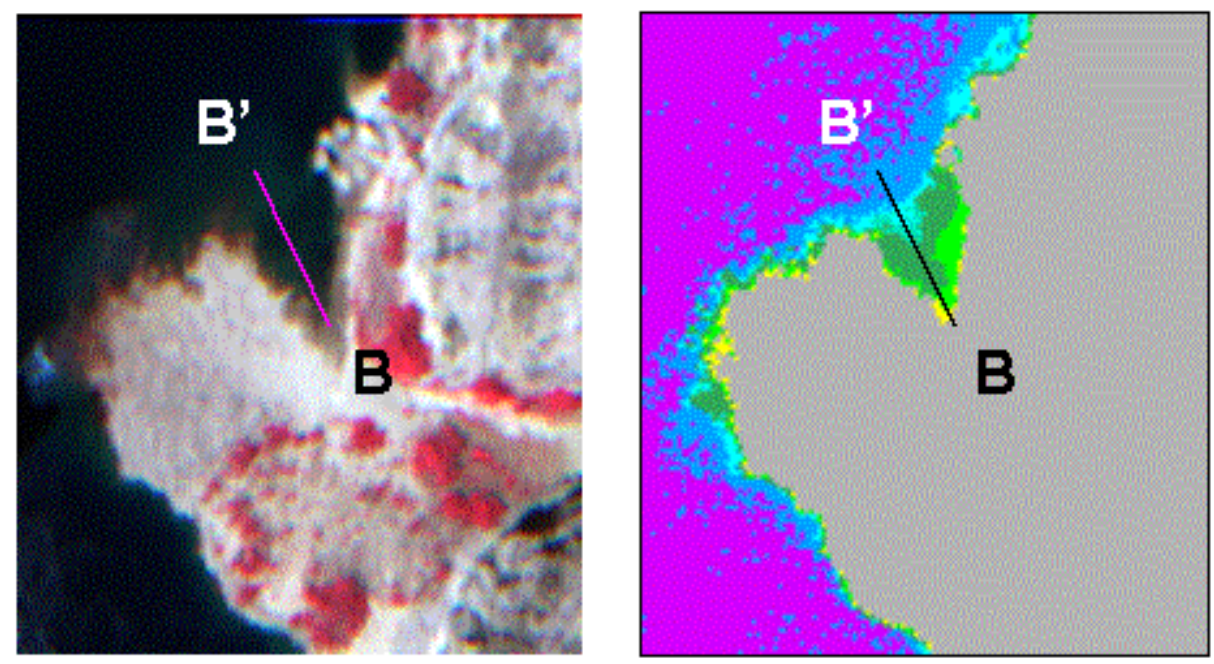

Figure 8a. ATM CIR image (left) and color-coded airborne-TIR water-temperature map (right) of the left bank of the Colorado River at the mouth of Tatahatso Wash (river mile 43.2). Image width is 128 meters. Land is gray, water colors correspond to temperature scale shown below.

TBMPERATURE $\left({ }^{\circ} \mathrm{C}\right)$ COLOR SCALE

$=\begin{array}{lllllll}12.5 & 13.0 & 13.5 & 14.0 & 17.0 & 20.0 & 23.6\end{array}=25.4$
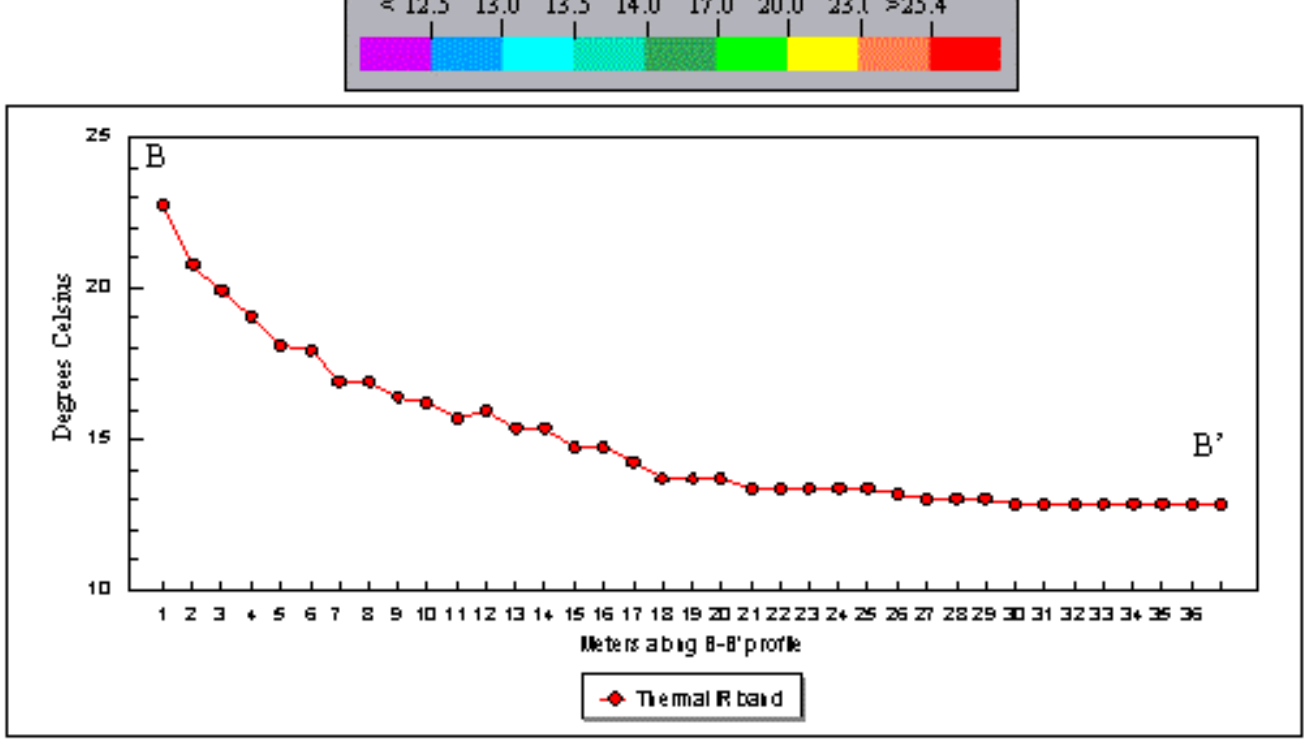

Figure $8 \mathrm{~b}$. Calibrated, airborne TIR water temperatures along profile $\mathrm{B}-\mathrm{B}$ '. 


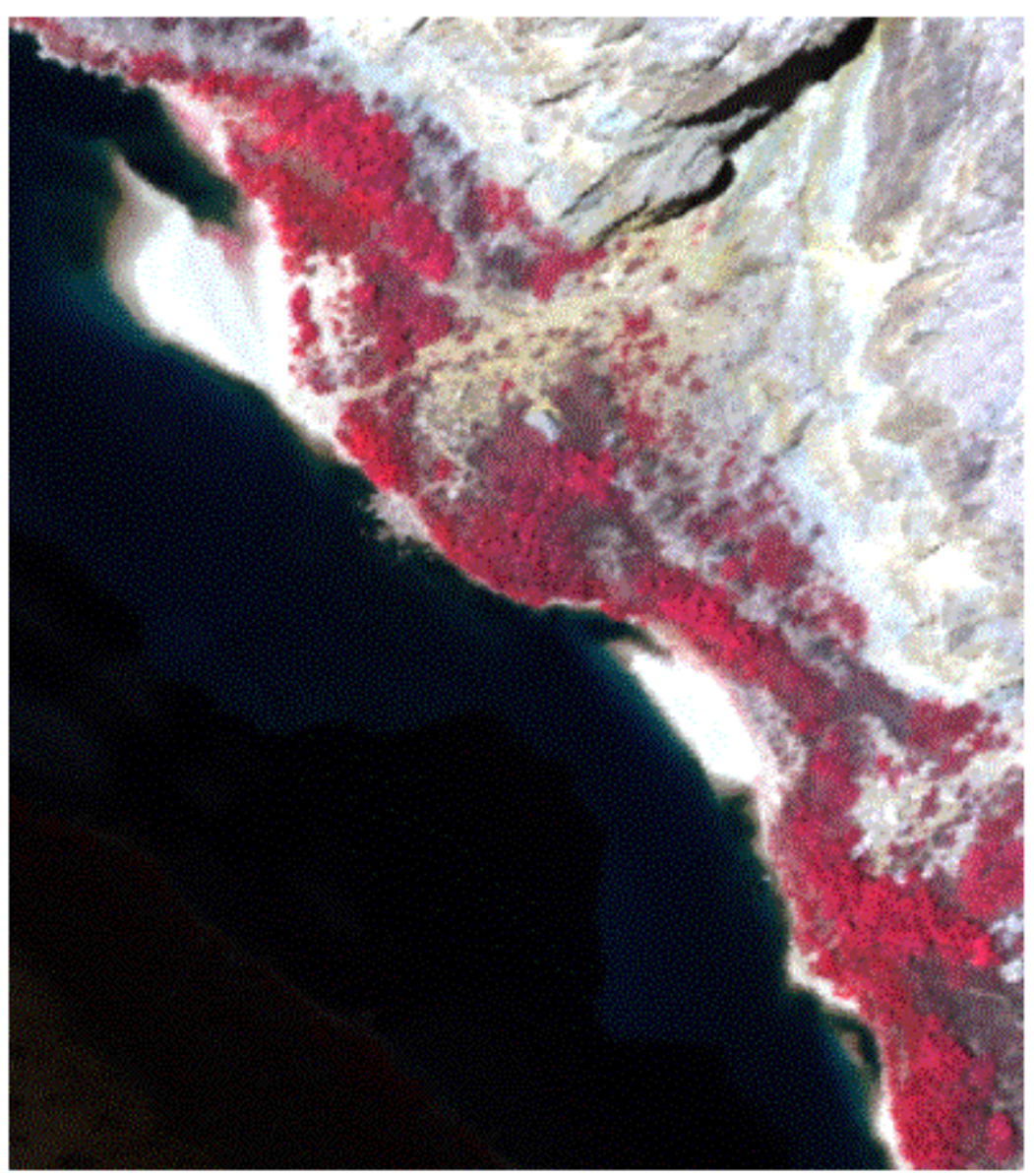

Figure 9a. ATM CIR image showing two re-attachment (eddy) bars on the left bank of the Colorado River just north of President Harding

Rapids at river mile 43.2 . Image width is 296 meters. 


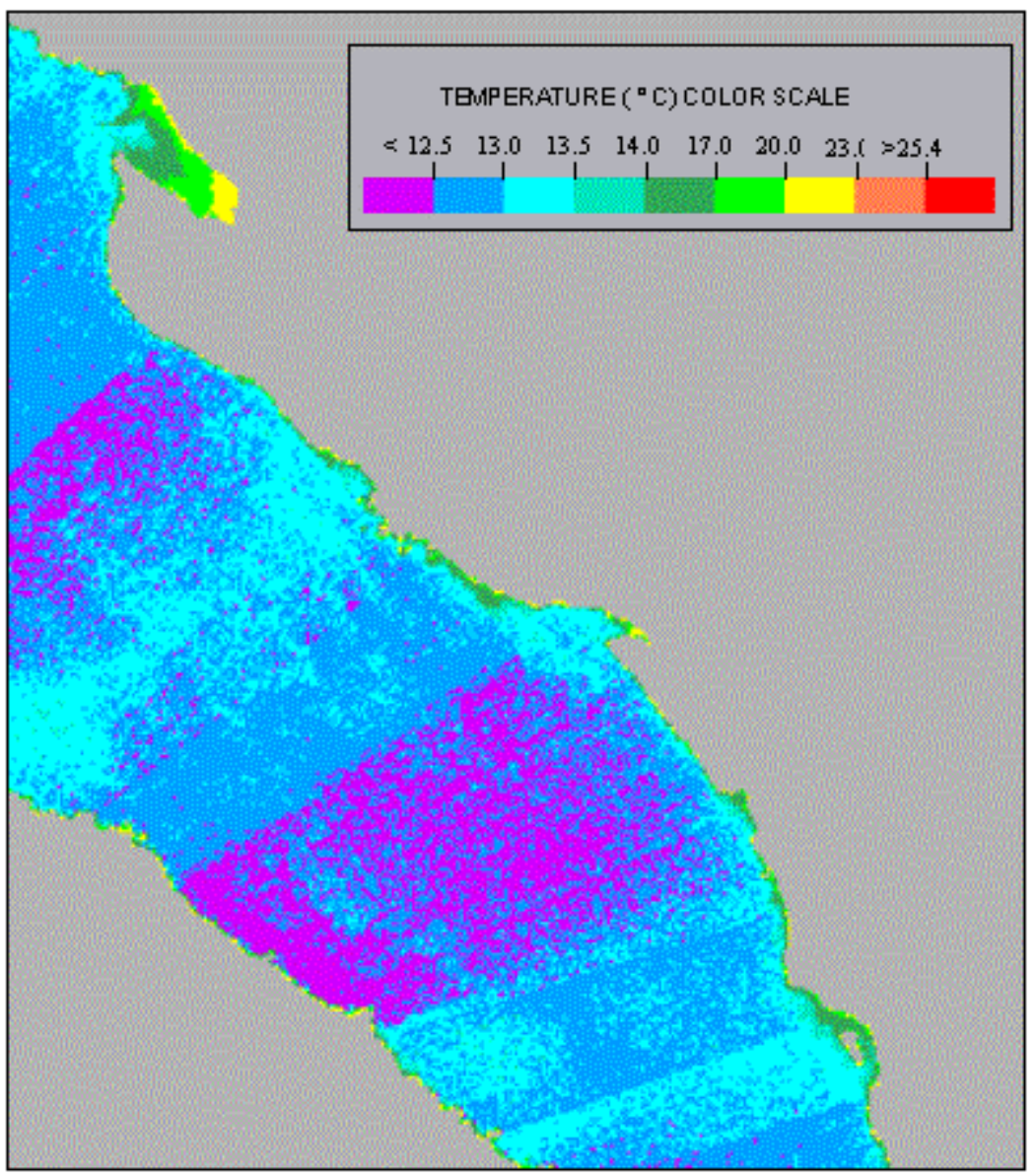

Figure $9 \mathrm{~b}$. Color-coded airbome-TIR water-temperature map of area depicted in Figure 9a, showing a large, wam-water channel behind the northern eddy bar shown in Figure 9a. Image width is 296 meters. Land is gray; water colors correspond to temperature scale shown. Scanline noise very obvious in this reach. 


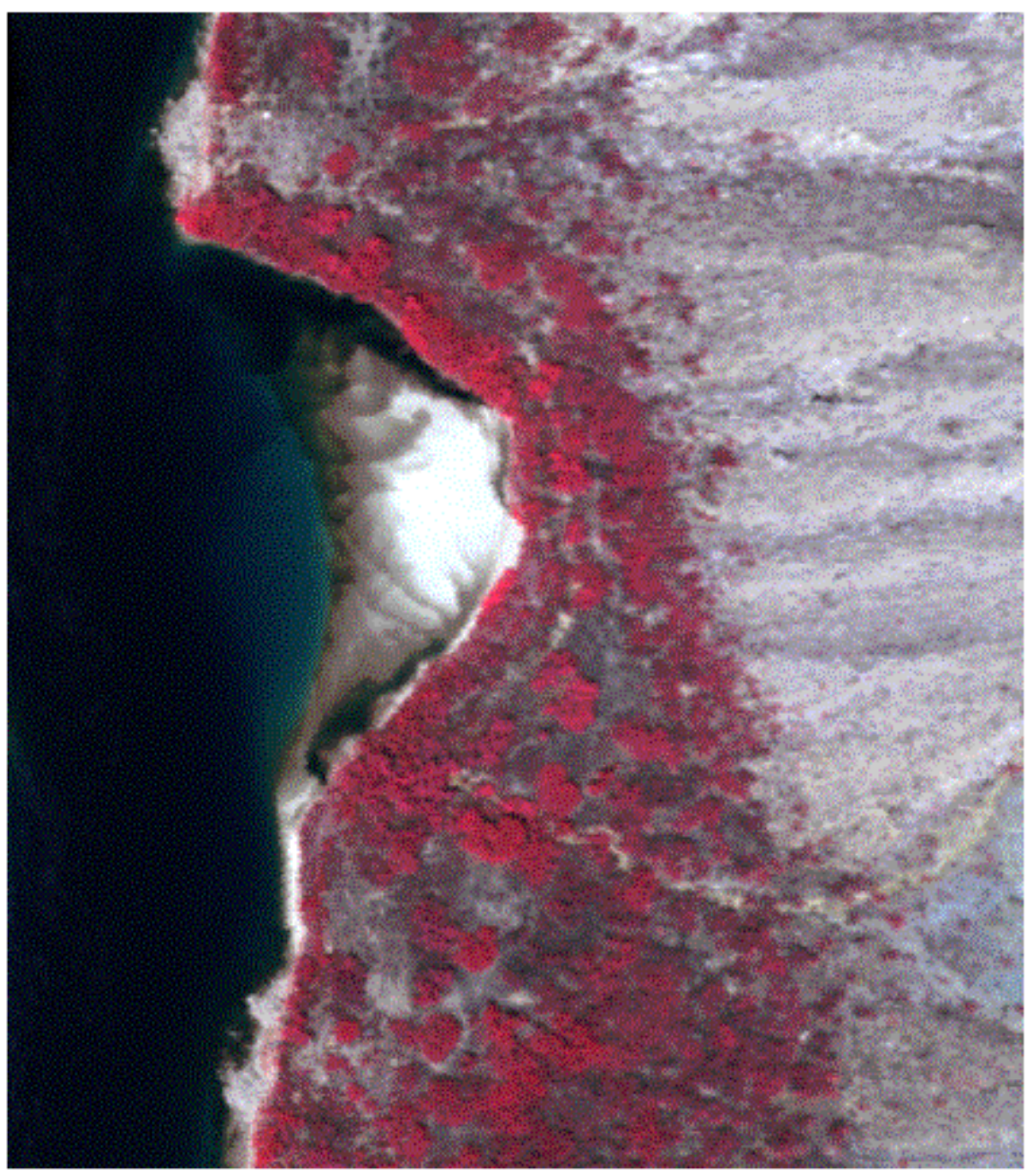

Figure 10a. ATM CIR image of the left bank of the Colorado River at river mile 50.2, showing return-current channel and a possible isolated backwater channel behind the large eddy sandbar that has easily visible, large sandwaves on its shallow-water surface. Image width is 296 meters. 


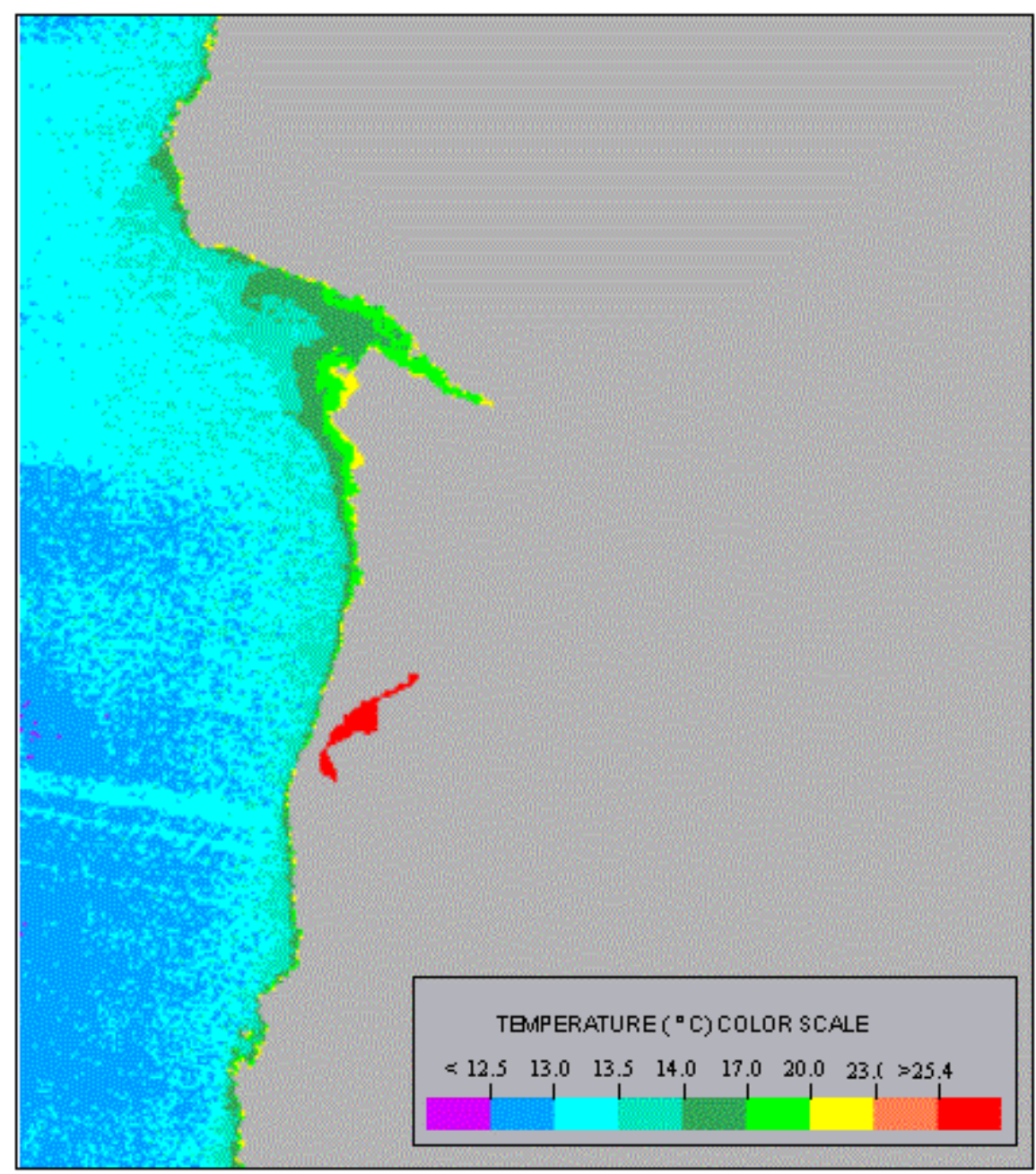

Figure 10b. Color-coded airbome-TIR water-temperature map of area depicted in Figure 10a, showing an isolated (due to low-flow conditions) backwater with very high temperatures. Image width is 296 meters. Land is gray; water colors correspond to temperature scale shown. 


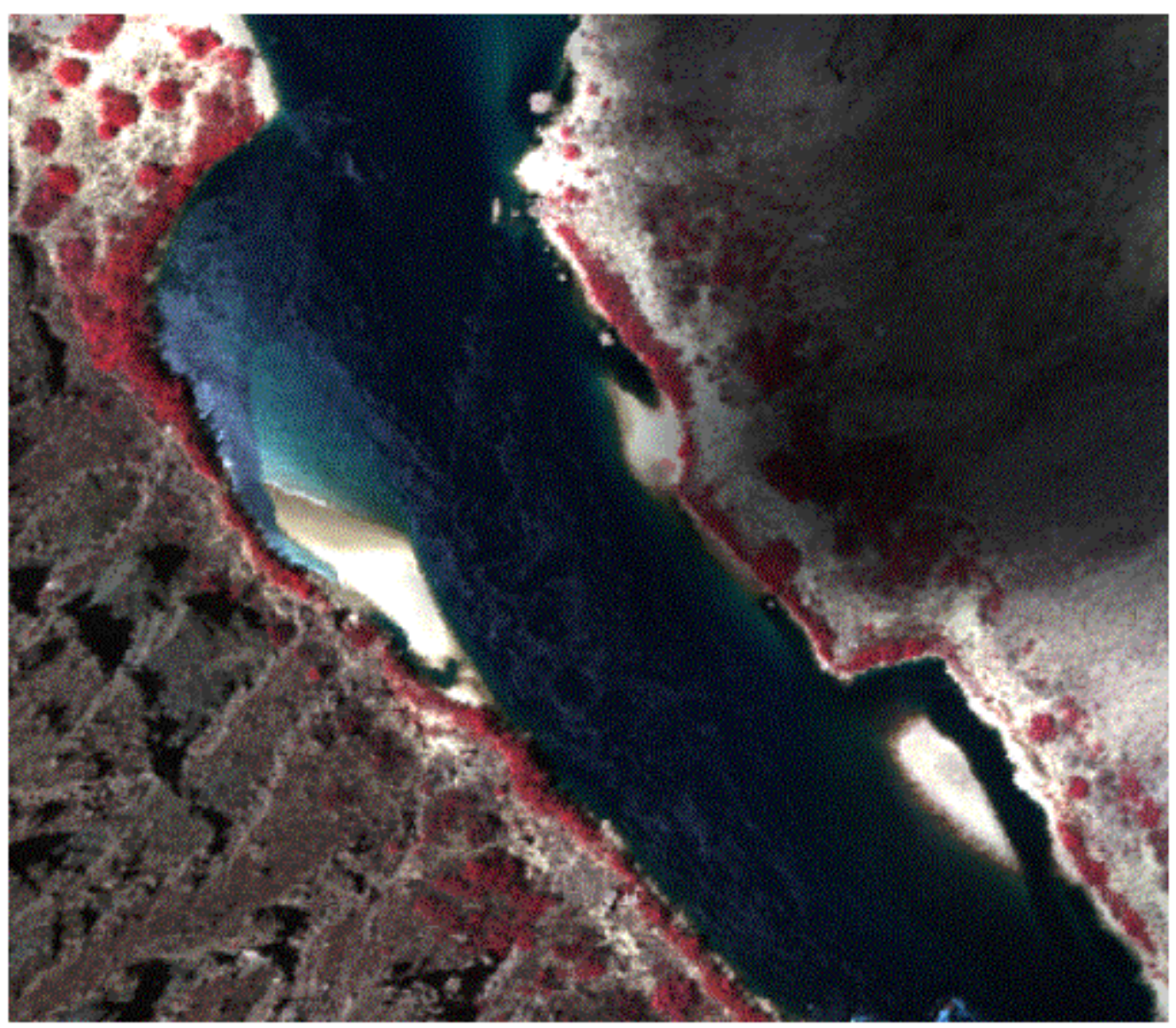

Figure 11a. ATM CIR image of Colorado River south of Anatubi Canyon at river mile 58, showing shallow-water sandwaves on the eddy sandbars and backwater channels. Image width is 394 meters. 


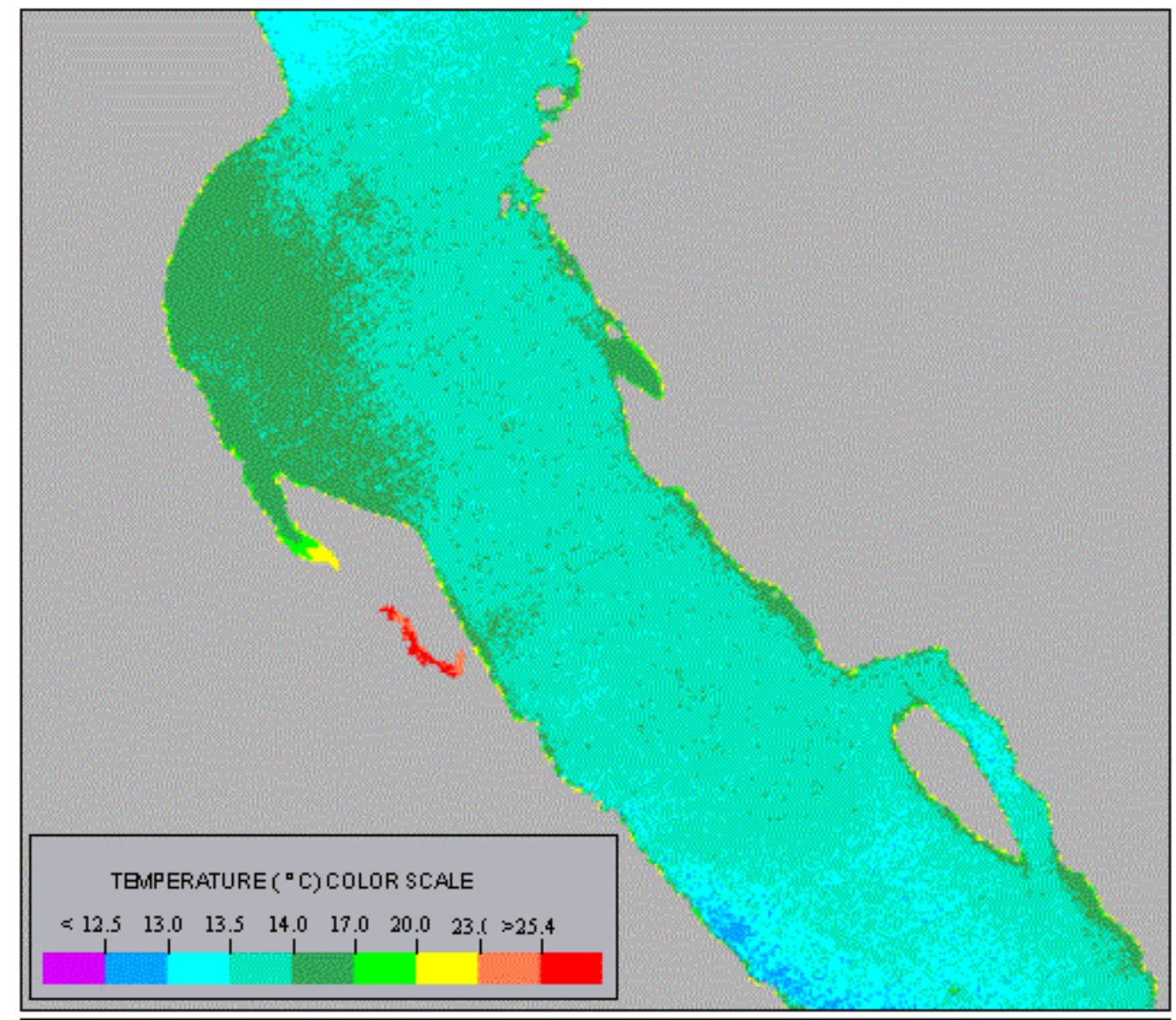

Figure 11b. Color-coded airbome-TIR water-temperature map of area depicted in Figure 11 a showing return-current channel, part of which has been cut off from the main stem due to low-flow conditions. Image width is 394 meters. Land is gray, water colors correspond to temperature scale shown. 


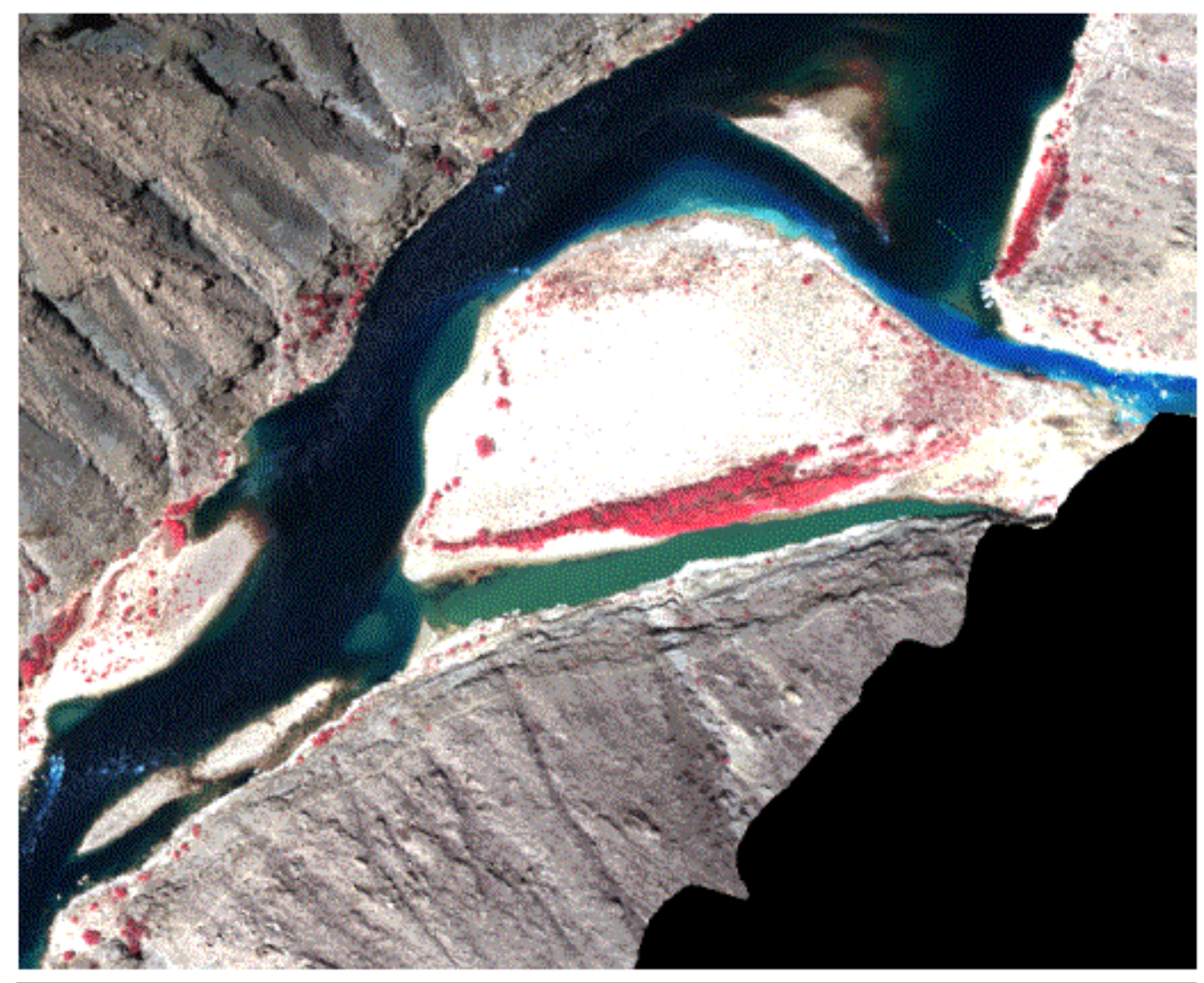

Figure 12a. ATM CIR image of the confluence of the Little Colorado River (LCR; to the right) with the mainstem (trending NE-SW here) of the Colorado River at river mile 61.5. Color differences in water color can be seen in the Little Colorado River's two water channels: the carbonate-rich LCR water is shades of blue and the algae-rich water is shades of green. Image width is 659 meters. 


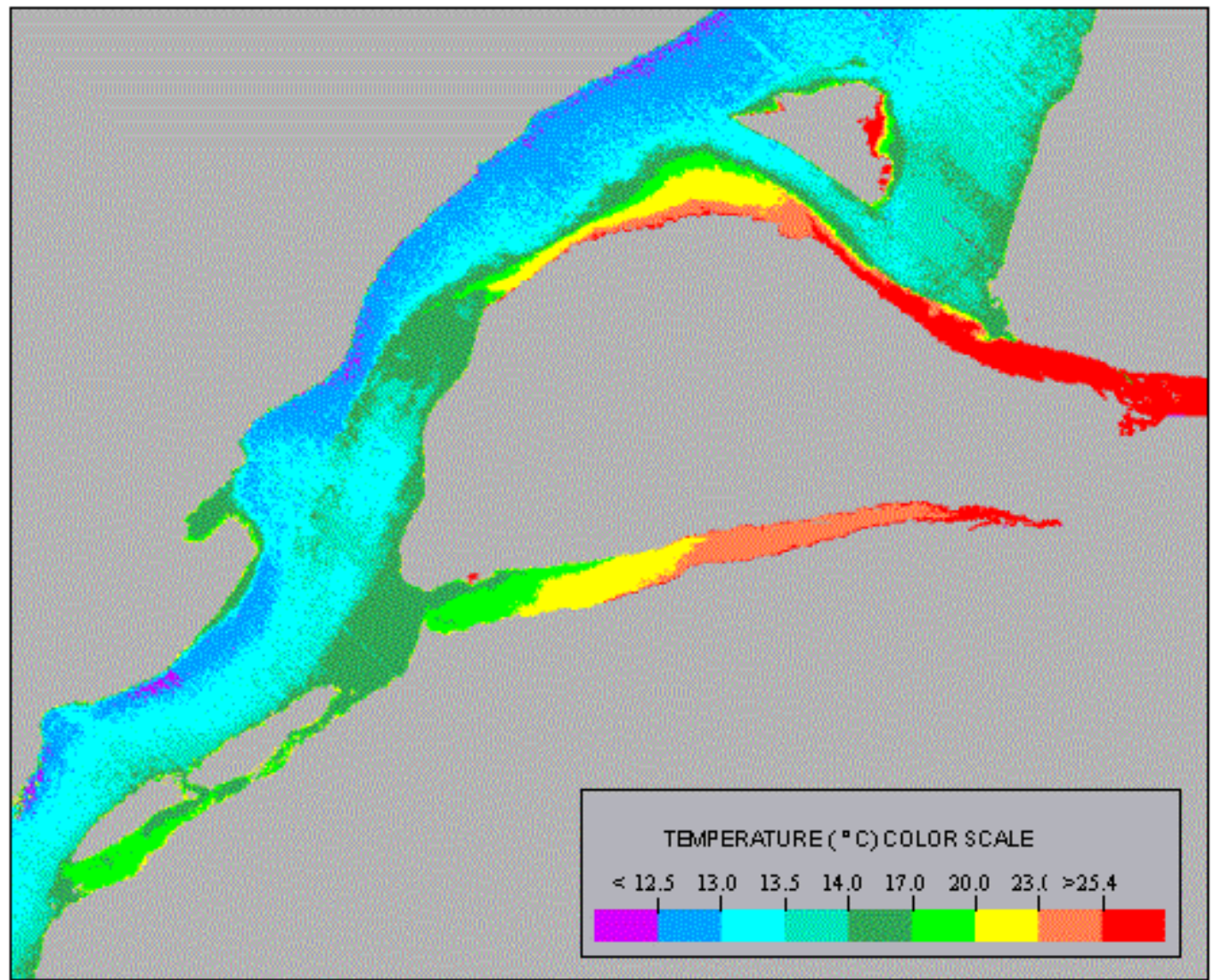

Figure 12b. Color-coded airbome-TIR water-temperature map of area depicted in Figure 12a, showing the local heating effects of the Little Colorado River on the main stem and on the backwaters immediately downstream. Image width is 659 meters. Land is gray; water colors correspond to temperature scale shown. 


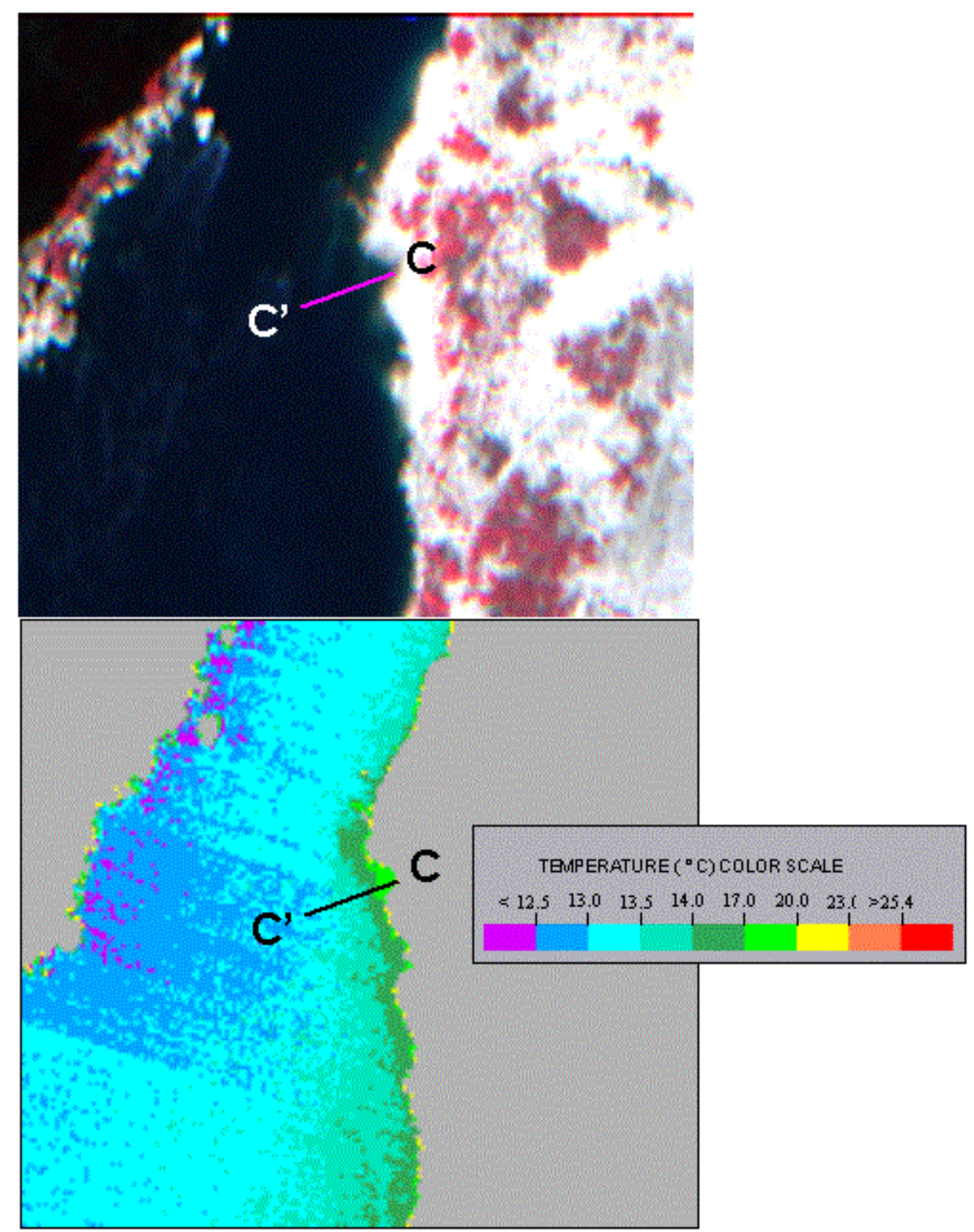

Figure 13a. ATM CIR image (top) and color-coded airborne-TIR water-temperature map (bottom) of the Colorado River at river mile 64, showing location of a themistor string (C-C') that was operating the day before the ATM overflight. Image width is 182 meters. Land is gray, water colors correspond to temperature scale shown. 


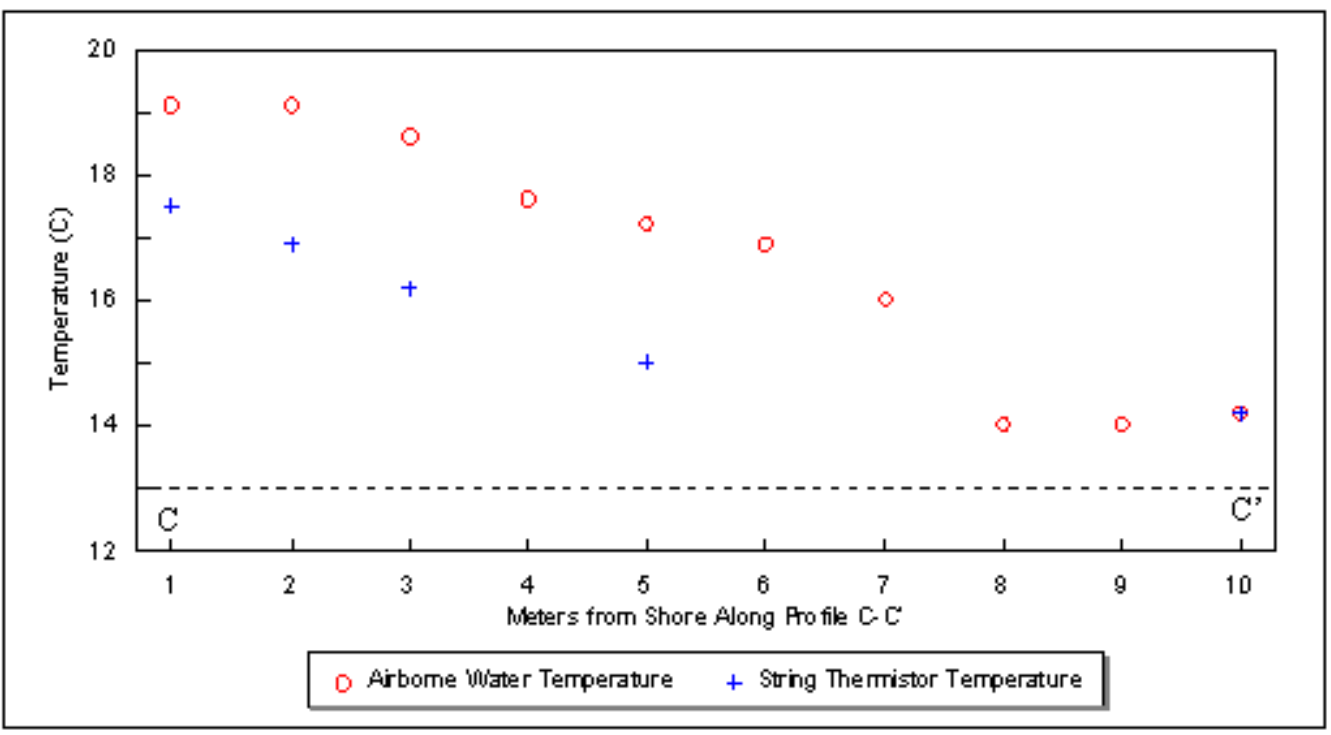

Figure 13b. Comparison of ATM airborne-TIR water temperatures at 1:30PM on July $24^{\text {th }}$, 2000 with themistor string temperatures (represented by the profile $\mathrm{C}$-C') recorded the day before the overflight. There is a 2 degree difference between these data except at the main stem (10 $\mathrm{m}$ distance). It is unknown whether this disparity can be attributed to differences between July $24^{\mathrm{t}}$ (thermistor reading) and $25^{\mathrm{t}}$ (overflight), but overflights on July $24^{\mathrm{th}}$ were cancelled because of cloud cover, which suggests that sunlight and its heating effects were more limited on July $24^{\mathrm{t}}$. 


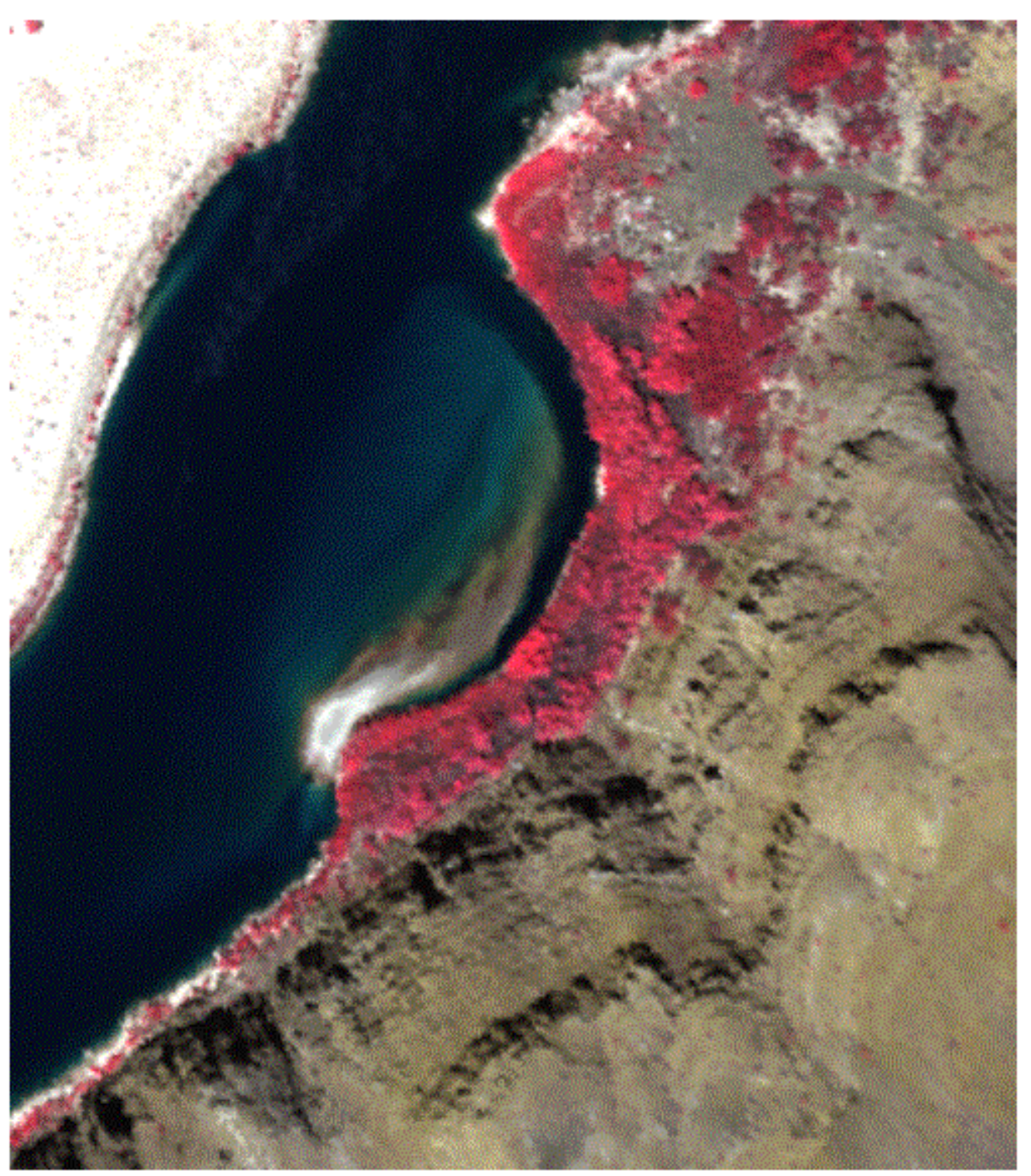

Figure 14a. ATM CIR image of the Colorado River north of Tanner Rapid at river mile 68 , showing an embayment with sandwaves on the shallow-water portions of the river-left eddy sandbar. Image width is 296 meters. 


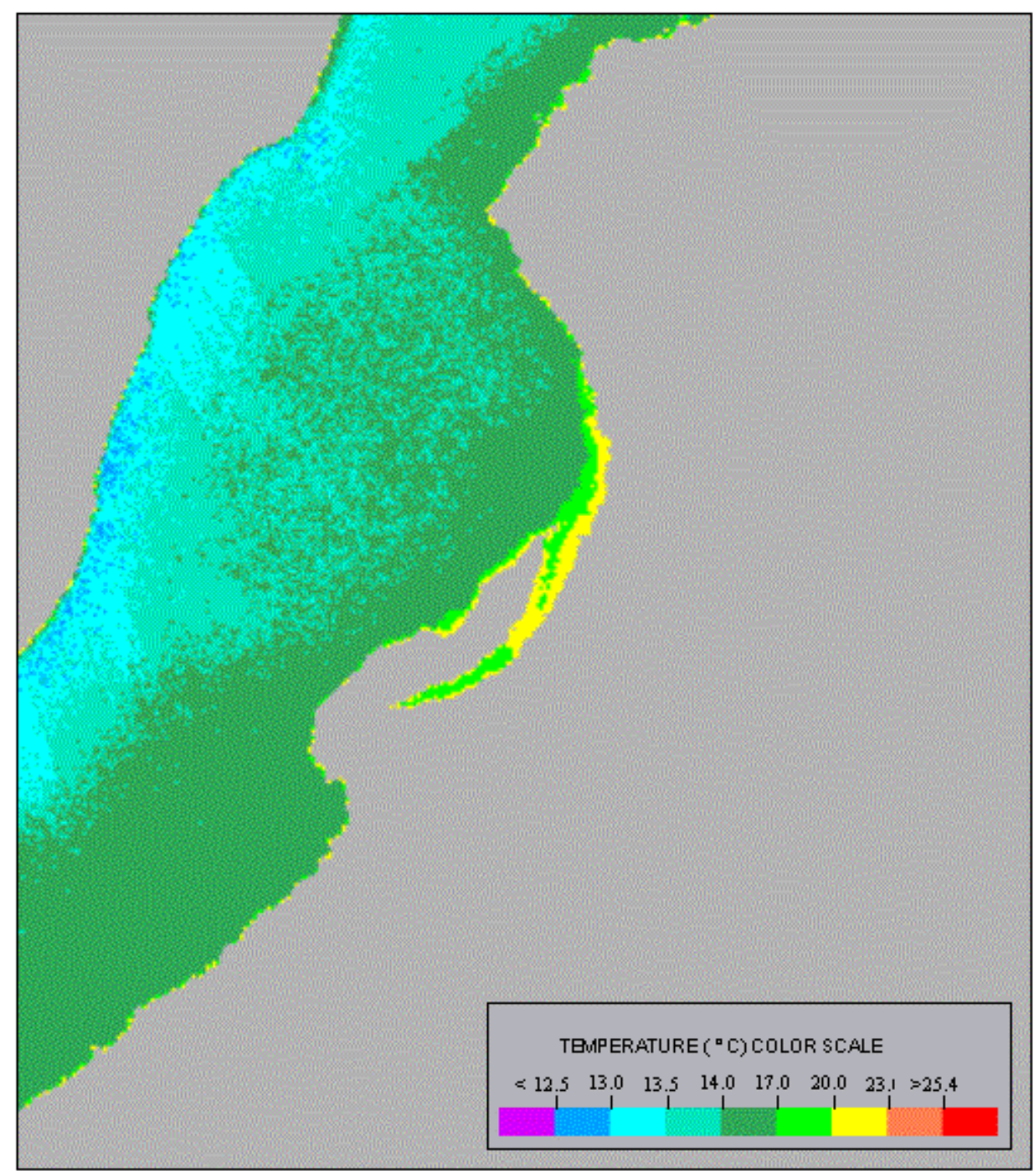

Figure 14b. Color-coded airbome-TIR water-temperature map of area depicted in Figure 14a, showing the heating effects within the shallow backwater area. Image width is 296 meters. Land is gray; water colors correspond to temperature scale shown. 


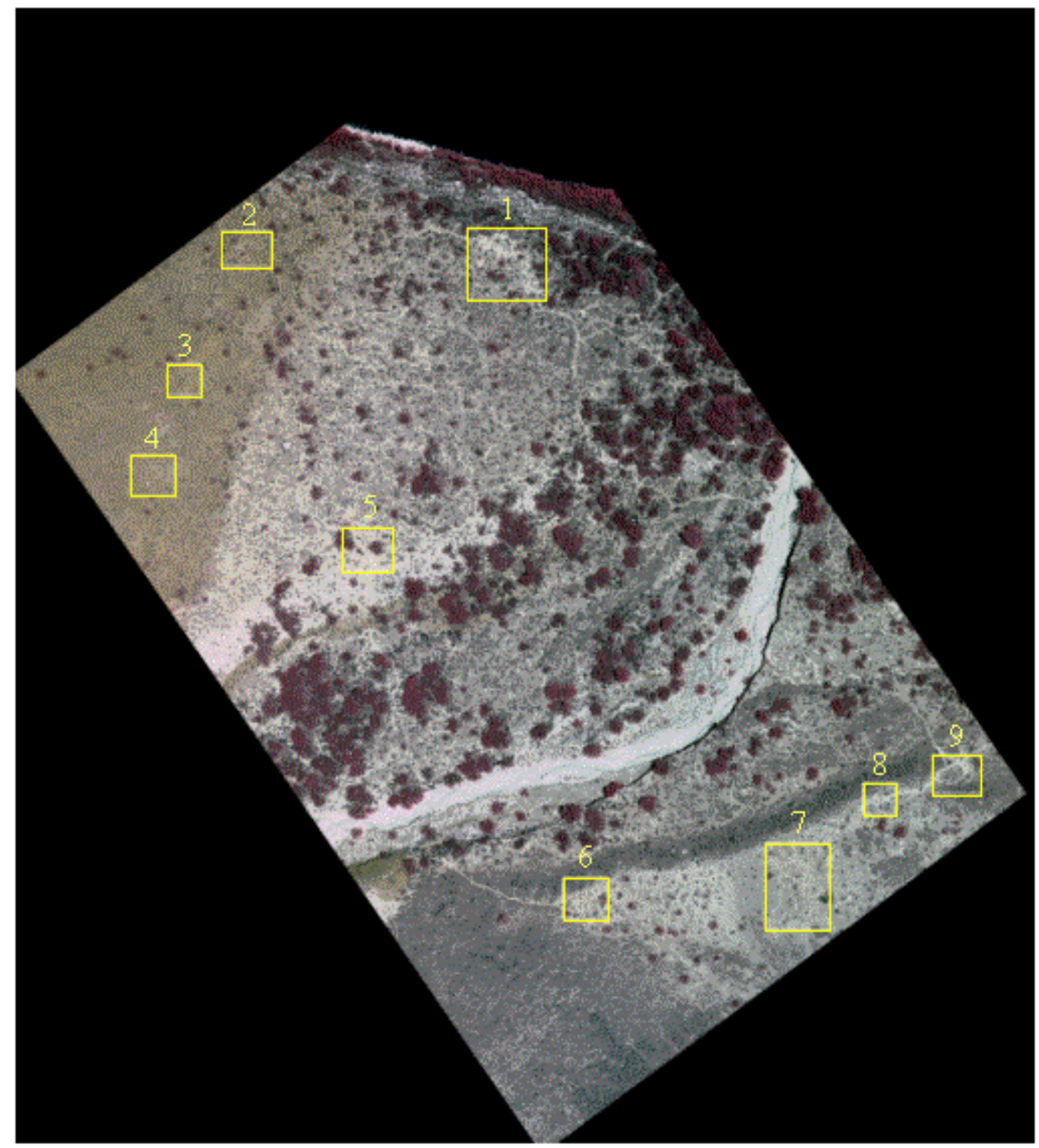

Figure 15. Aerial CIR orthophoto image of Unkar delta on the right bank of the Colorado River at river mile 72.6. Image resolution is $11 \mathrm{~cm}$. Image width is 493 meters. Numbered boxes contain archaeological structures; only areas 1 through 5 are contained within the ATM TIR coverage. 


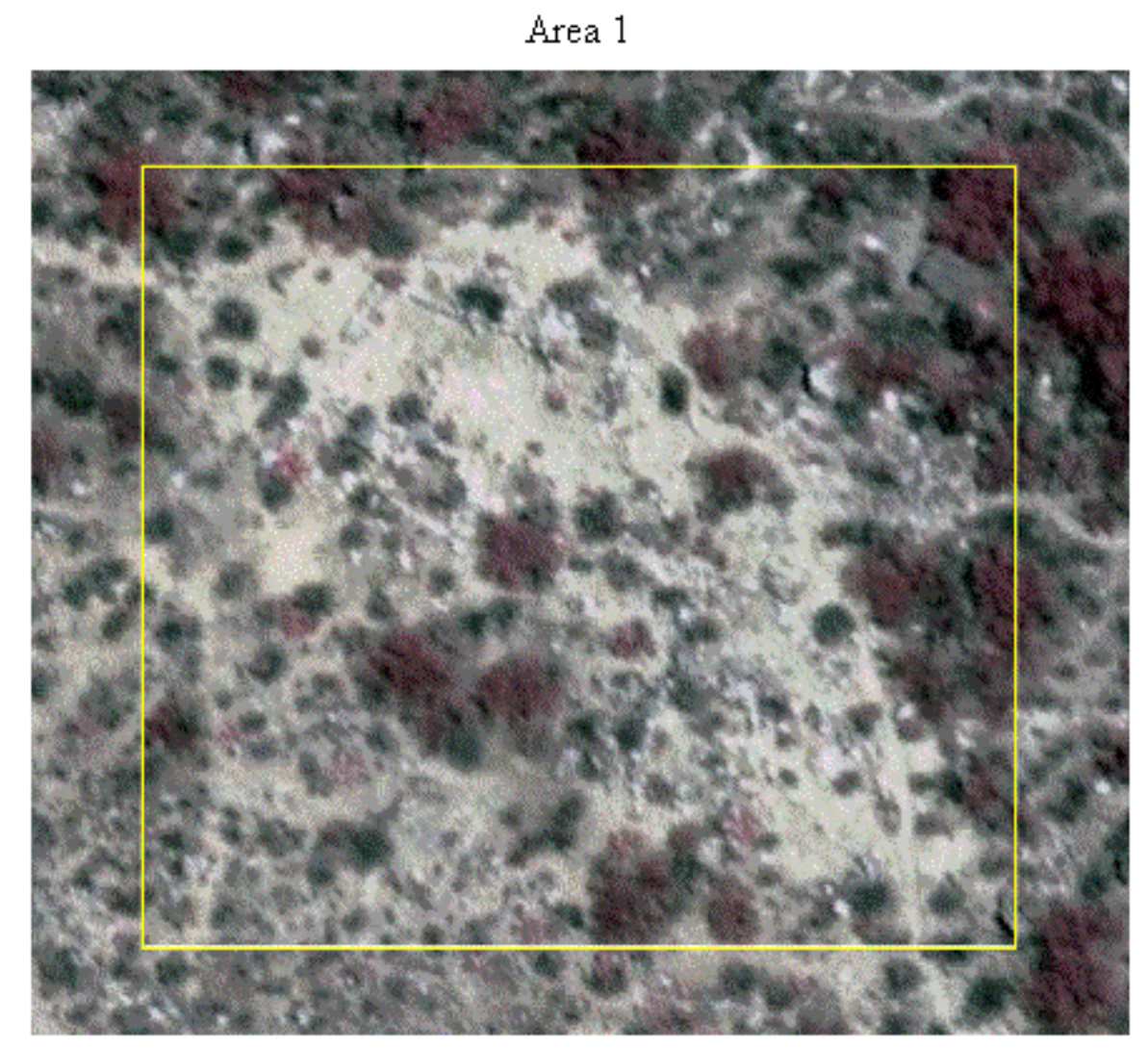

Figure 16. Enlargement of area 1 shown in Figure 15. Image resolution is $11 \mathrm{~cm}$; image width is 48.4 meters. Multiple archaeological foundations are easily visible at this resolution. 

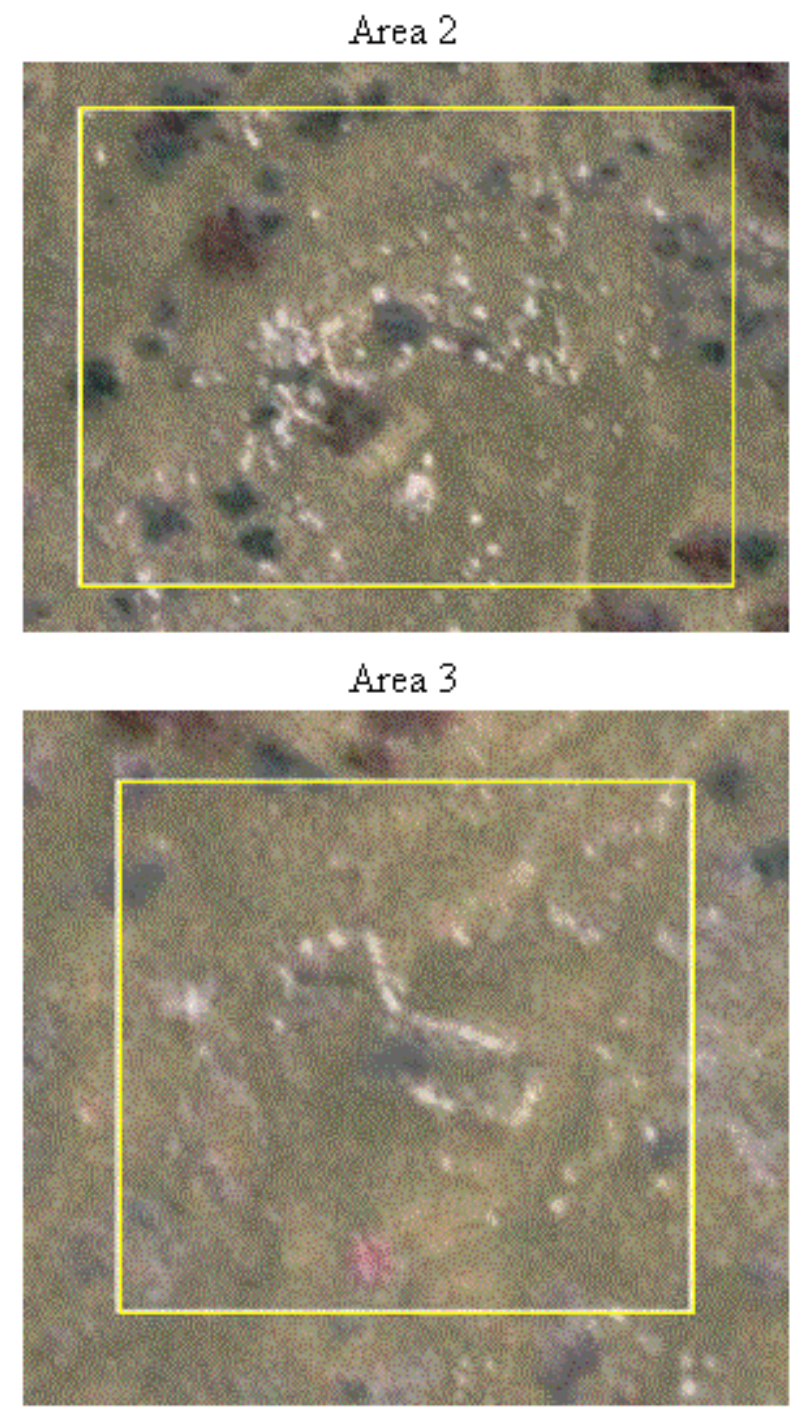

Figure 17. Enlargement of areas 2 and 3 shown in Figure 15 . Image resolution is $11 \mathrm{~cm}$. Image width is 27.9 meters for area 2 and 21.9 meters for area 3 . 
Area 4

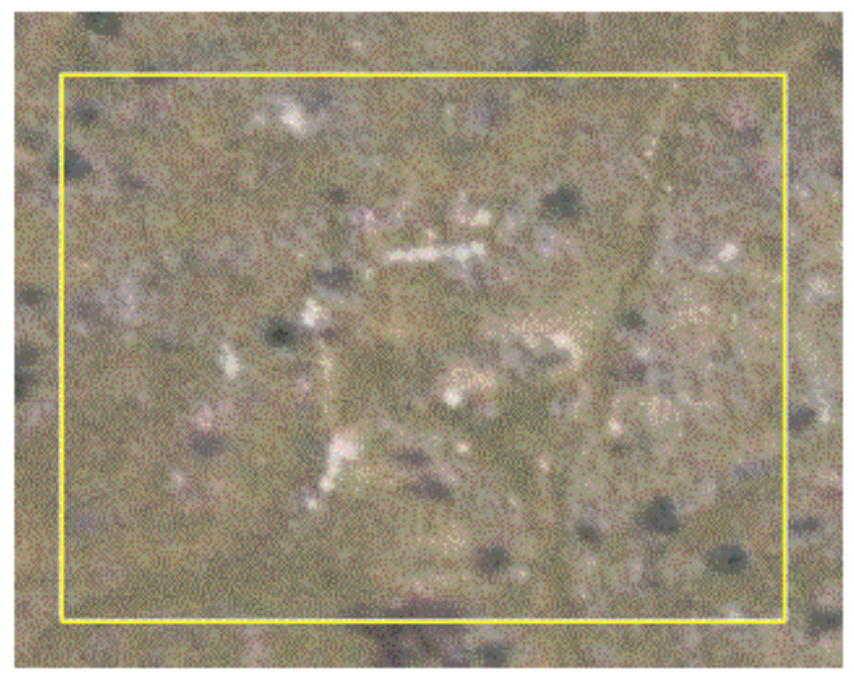

Area 5

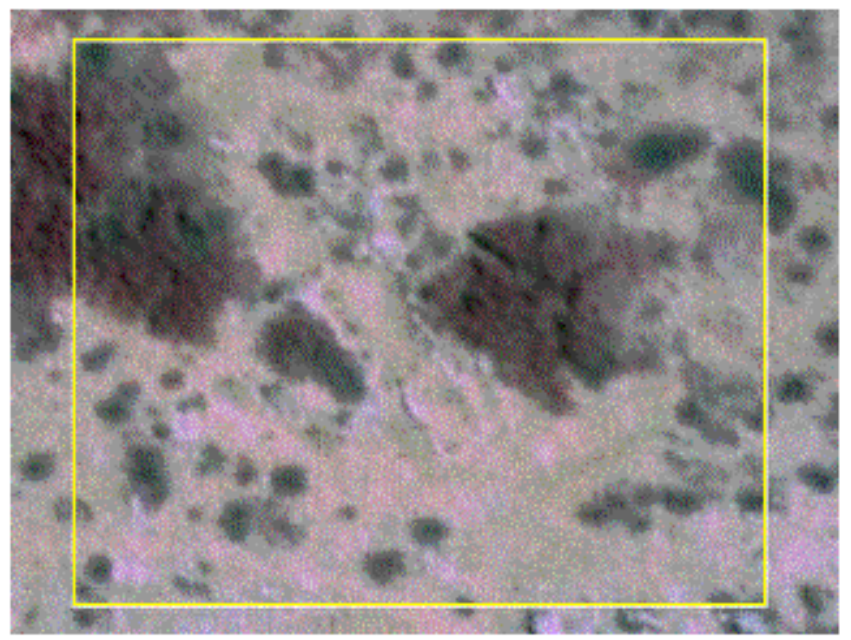

Figure 18. Enlargements of areas 4 and 5 shown in Figure 15. Image width is 24.4 meters for area 4 and 29.4 meters for area 5 . The image of area 5 had to be enhanced different from the other archaeological areas due to the saturated (bright) surface material contained at this locale. 


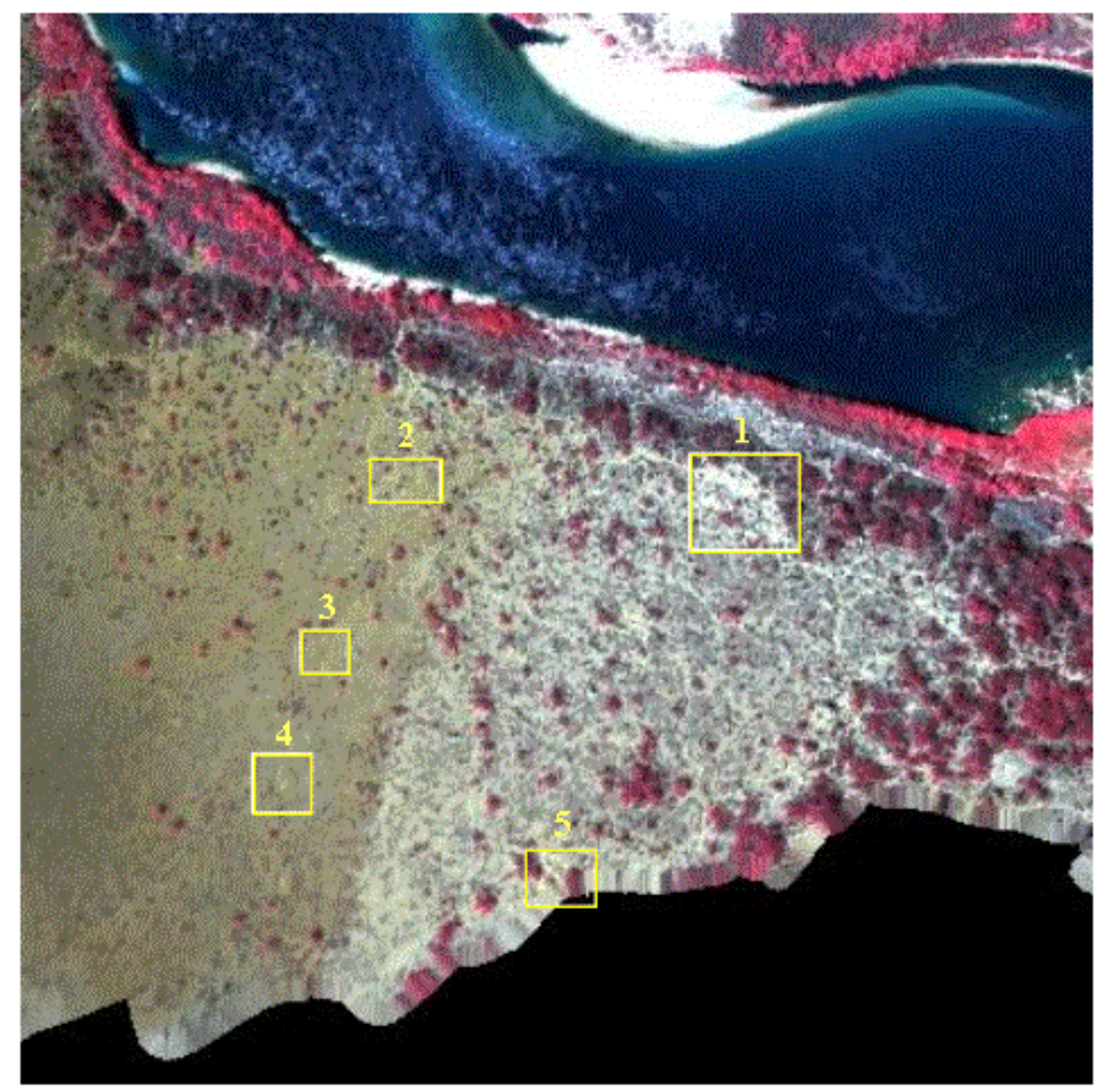

Figure 19. ATM CIR orthophoto image of Unkar delta on the right bank of the Colorado River at river mile 72.6. Image resolution is $100 \mathrm{~cm}$. Image width is 400 meters. Boxes labeled 1 through 5 correspond in locations of archaeological structures located in Figure 15. The 100$\mathrm{cm}$ ATM visible through short-wave infrared image data do not show indications of the archaeological structures seen in Figures 16-18. 


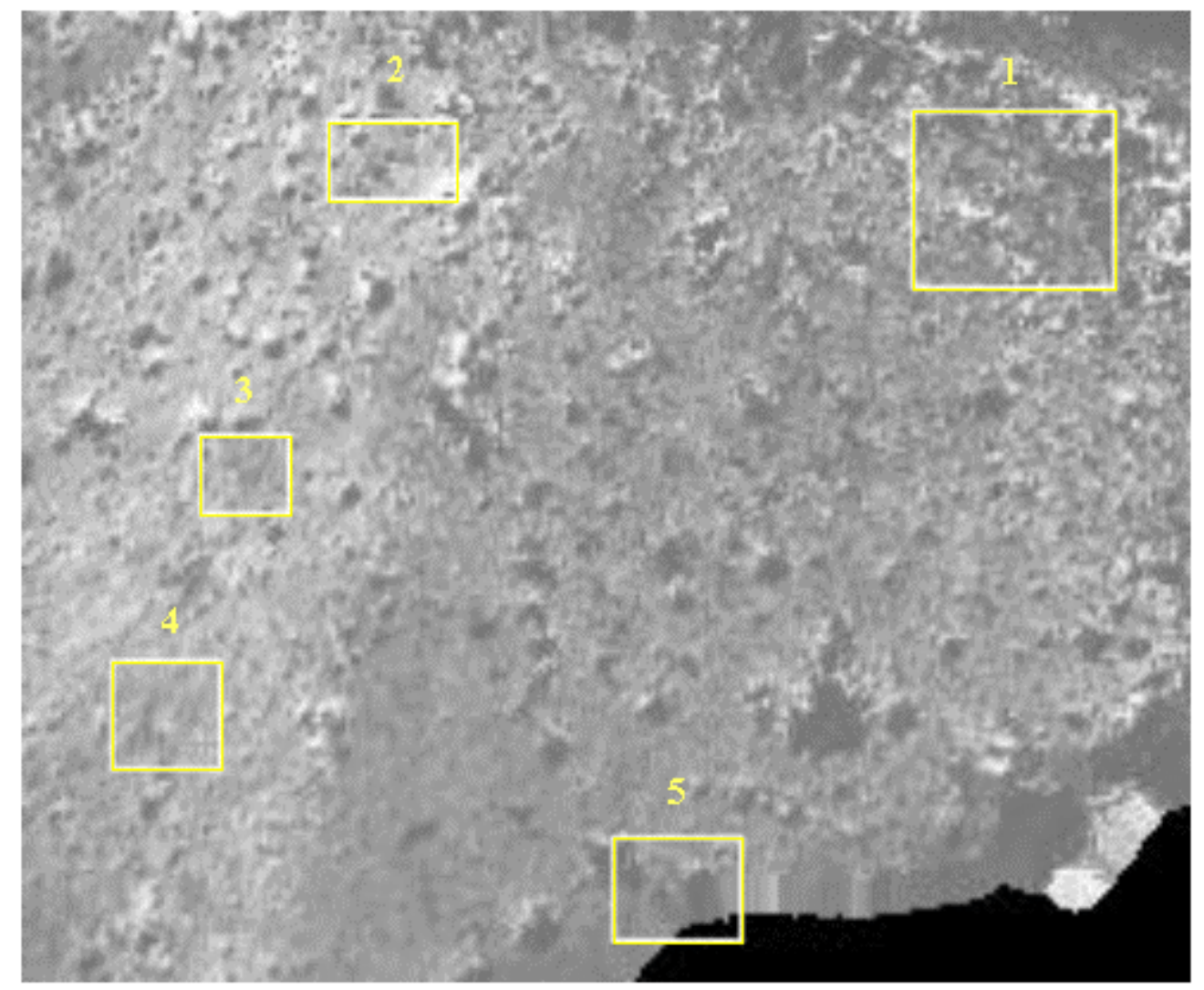

Figure 20. ATM TIR orthophoto of Unkar delta on the right bank of the Colorado River at river mile 72.6. Image resolution is $100 \mathrm{~cm}$; image width is 238 meters. Within the boxed areas there are no themal anomalies that correspond to the archaeological structures observed in Figures 16 and 18 . 

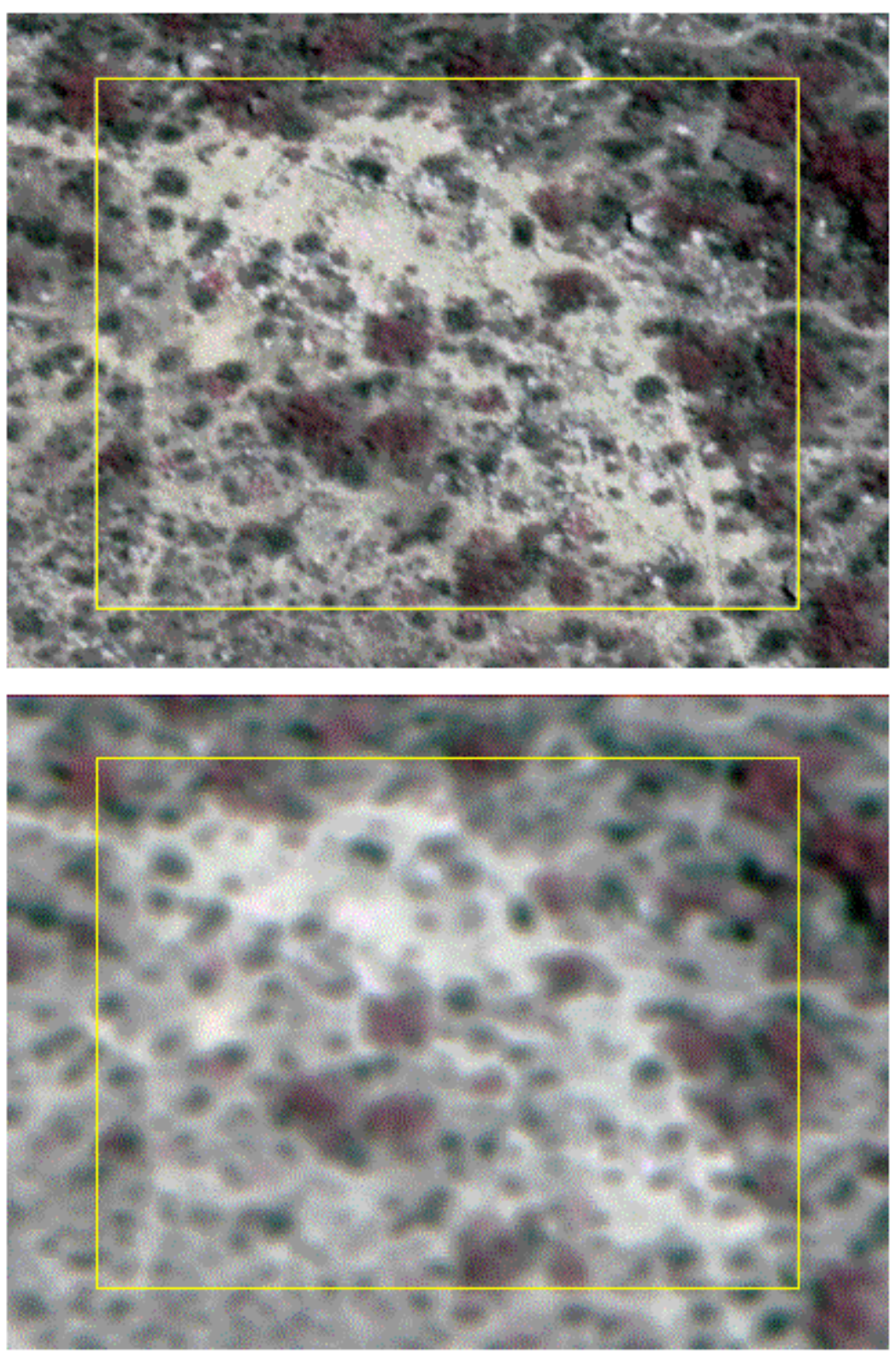

Figure 21. Archaeological area 1 on Unkar delta as shown in Figure 16. Image resolution is $11 \mathrm{~cm}$ (top) and $100 \mathrm{~cm}$ (bottom). Image width is 48.4 meters. Multiple archaeological foundations are easily visible at $11-\mathrm{cm}$ resolution, but not identifiable at $100-\mathrm{cm}$ resolution, which was produced synthetically by filtering the $11-\mathrm{cm}$ resolution data. 

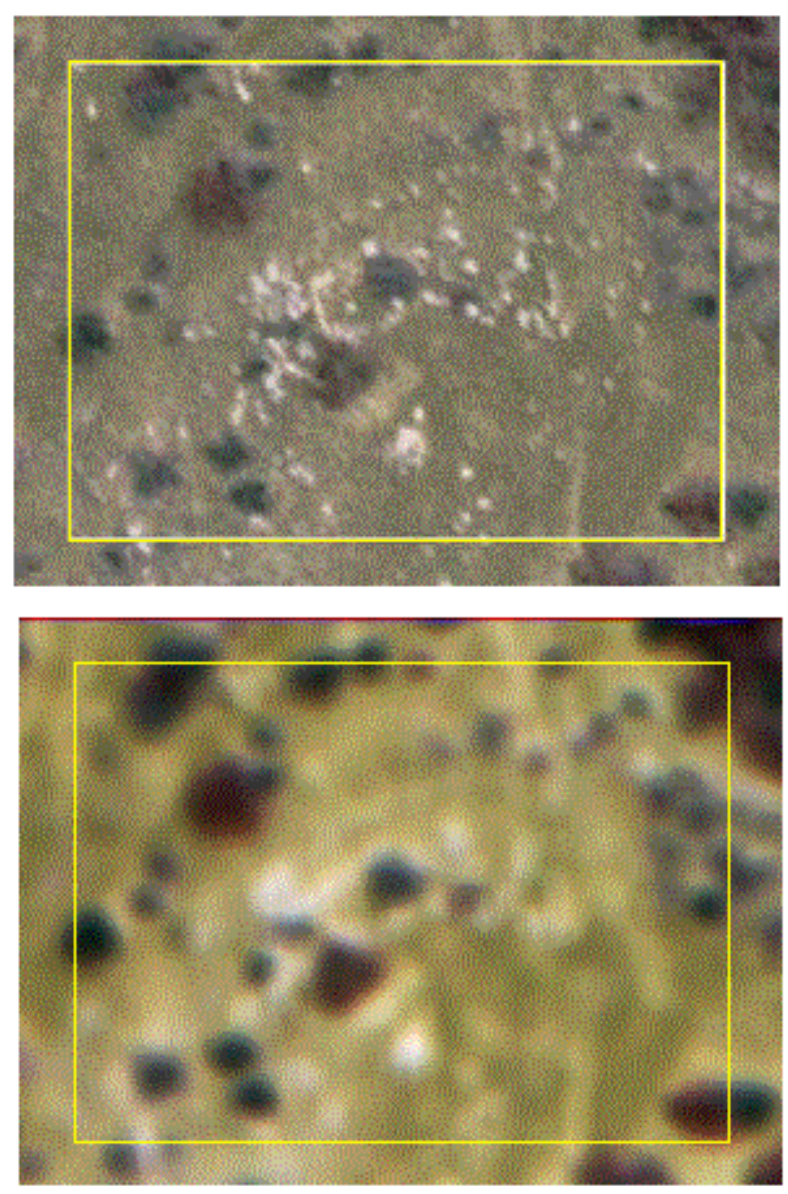

Figure 22. Archaeological area 2 on Unkar delta as shown at top of Figure 17. Image resolution is $11 \mathrm{~cm}$ (top) and $100 \mathrm{~cm}$ (bottom). Image width is 27.9 meters. Multiple archaeological foundations are easily visible at $11-\mathrm{cm}$ resolution, but not unique from natural color patterns on the surface at $100-\mathrm{cm}$ resolution, which was produced synthetically by filtering the $11-\mathrm{cm}$ resolution data. 

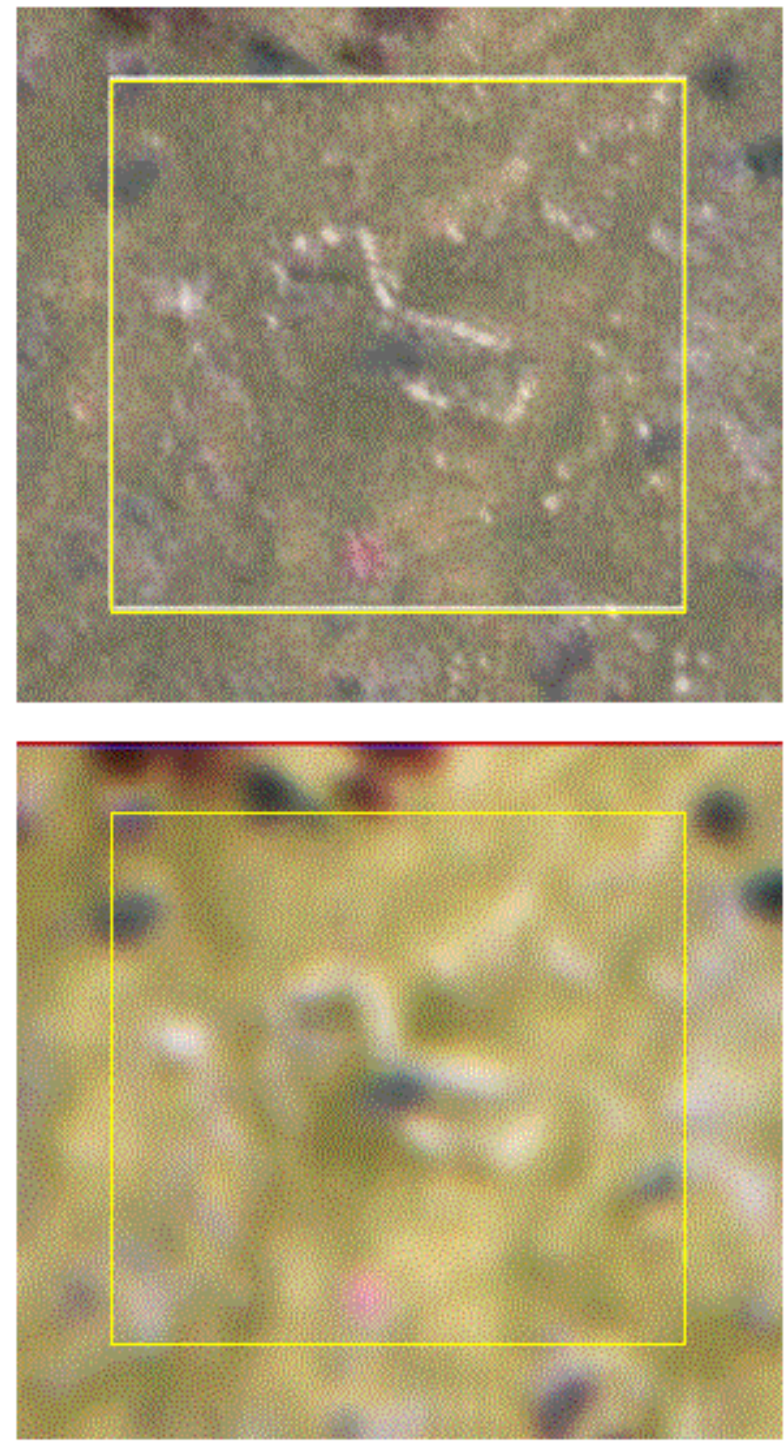

Figure 23. Archaeological area 3 on Unkar delta as shown at bottom of Figure 17. Image resolution is $11 \mathrm{~cm}$ (top) and $100 \mathrm{~cm}$ (bottom). Image width is 21.9 meters. An

archaeological foundation is easily visible at $11-\mathrm{cm}$ resolution, but much less distinguishable from natural alignments of rocks (produced by surface runoff) at $100-\mathrm{cm}$ resolution, which was produced synthetically by filtering the $11-\mathrm{cm}$ resolution data. 